\title{
Harmonic Effects Due to the High Penetration of Photovoltaic Generation into a Distribution System
}

\author{
Jorge Luiz Moreira Pereira ${ }^{1, *(D)}$, Adonis Ferreira Raiol Leal ${ }^{2} \mathbb{D}$, Gabriel Oliveira de Almeida ${ }^{3}$ and \\ Maria Emília de Lima Tostes 4 \\ 1 Department of Engineering_Protection and Control, Eletrobras-Eletronorte System-OTLPV, \\ Barcarena 68445-000, PA, Brazil \\ 2 Department of Electrical and Biomedical Engineering, Federal University of Pará, Belém 66075-110, PA, \\ Brazil; adonisleal@ufpa.br \\ 3 Department of Project Engineering and Installation, Company Sansol Engineering, Belém 66053-360, PA, \\ Brazil; gabriel-di-oliveira@hotmail.com \\ 4 Electrical and Computer Engineering Department, Federal University of Pará, Belém 66075-110, PA, Brazil; \\ tostes@ufpa.br \\ * Correspondence: jorgepereira@ufpa.br or jorge.pereira@eletronorte.gov.br; Tel.: +55-091-99173-2383
}

Citation: Pereira, J.L.M.; Leal, A.F.R.; Almeida, G.O.d.; Tostes, M.E.d.L. Harmonic Effects Due to the High Penetration of Photovoltaic Generation into a Distribution System. Energies 2021, 14, 4021. https://doi.org/10.3390/en14134021

Academic Editor:

Gian Giuseppe Soma

Received: 24 May 2021

Accepted: 29 June 2021

Published: 4 July 2021

Publisher's Note: MDPI stays neutral with regard to jurisdictional claims in published maps and institutional affiliations.

Copyright: (C) 2021 by the authors. Licensee MDPI, Basel, Switzerland. This article is an open access article distributed under the terms and conditions of the Creative Commons Attribution (CC BY) license (https:/ / creativecommons.org/licenses/by/ $4.0 /)$.
Abstract: The growth in global electricity demand has expanded the search for new energy resources. Renewable sources such as photovoltaic (PV) systems have proven to be major alternatives. PV generators connected to distribution grids have exhibited significant growth in the last decade, so it is essential to analyse the impacts resulting from this increase. This work investigated the influence of high PV system penetration in distribution grids in terms of harmonic levels. In particular, this study addressed the distortions in voltage and current waveforms in the presence and absence of PV generators connected to a distribution grid. Additionally, the total harmonic content and the individual harmonic frequencies of voltage and current were analysed. This study was performed with an IEEE 37 bus distribution system and the Open Distribution System Simulator software (OpenDSS). The results show that the voltage limits of some phases far away from a substation can exceed the limits. Furthermore, the total harmonic distortion (THD) and individual harmonic distortion (IHD) levels for voltage and current were significantly high for harmonics of the 3rd, 5th, and 7 th orders, where current levels violate the standard levels.

Keywords: energy; distribution; grid connected; generation; photovoltaic insertion

\section{Introduction}

Global energy demand is constantly growing. Consequently, the search for new energy alternatives is ever-present. The exhaustion of nonrenewable energy resources and environmental preservation necessitates an increasing need for the development of renewable energy system technologies such as solar power. New advances in energy technology and the integration of renewable energy sources into distribution systems have contributed to a substantial improvement in the global generation of electricity in terms of quality and reliability. The use of renewable energy contributes to the reduction of greenhouse gas (GHG) emissions and to the minimisation of environmental impacts. Renewable energy sources help reduce the need for large energy generation systems and extensive transmission lines. Solar power systems or photovoltaic (PV) systems are frequently connected to distribution grids, and their use is increasing worldwide.

In [1], the National Association of Clean Air Agencies (NACAA), analysed and identified that photovoltaic generation causes fewer environmental impacts than energy from fossil fuels. Additionally, PV systems contribute to the reduction of greenhouse gas emissions. The use of PV systems can reduce power grid shortages, improve the voltage levels in consumer units, and decrease peak demand loads. However, the impacts of deploying PV systems on a large scale without planning can create power losses [1-5]. These 
losses are related to problems related to power quality, including harmonic distortions and unbalanced voltage and current $[6,7]$.

Many studies have identified the impacts of PV systems on power distribution grids $[2,3,6,8-11]$. The main issues caused by the insertion of PV systems are the introduction of harmonic components and variations in voltage and current levels [4-7,12-21].

In [7], the authors analysed the influences of power quality in a distribution grid due to the connection of PV systems. An analysis of the recorded data was performed regarding the harmonic content of the PV current; a computational model was developed to simulate various expansion scenarios and "more realistic" distribution network conditions.

In $[22,23]$, the authors presented methods and showed results on the improvement of harmonic voltage and current distortion in an electrical distribution system. According to the authors, the integration of photovoltaic generators generated harmonic distortions that affect electrical equipment and the power quality of the distribution grid.

In scientific literature $[6,24,25], \mathrm{PV}$ systems showed that the harmonic distortion of the current has an inverse relation to the solar incidence so that the injection of harmonics is higher when the system operates at low power.

The harmonic frequencies from inverters, along with other harmonics produced by nonlinear loads, have become a major concern for distribution systems. Similar studies have been reported in $[6,24,26]$, where the use of energy quality monitoring has become important to identify the different sources that can cause the appearance and presence of harmonic disturbances. Furthermore, it has been estimated that approximately $25 \%$ of the total electrical power system disturbances derive from harmonics, causing significant power losses in the electric power industry.

The results presented in [27] indicated that the total harmonic distortion (THD) in voltage at the same common coupling point where photovoltaic generation is connected tends to be identical to the THD in transformers employed in the generation connection. In $[28,29]$, the THD current varied according to the power provided, and it decreased when there was an increase in irradiance. As noted in [24,30], as the power offered by the photovoltaic system grew when compared to the power consumed by local loads, the power flow from the power grid to local loads decreased, raising the current THD values measured. The harmonics produced by photovoltaic systems are related to the concentration of harmonics requested by nonlinear loads, which depend on inverter loading [31].

The work developed in [32] emphasised harmonic current distortions caused by the high insertion of inverters in the distribution grid, showing that inverters can generate more relevant harmonic injections due to changes in solar radiation. Additionally, the work concluded that the harmonic injection produced by photovoltaic inverters spreads through a distribution system and can severely compromise its operation.

According to [33], the strong performance of PV systems in a distribution grid can lead to power variations at the coupling point and may exceed the limits defined by the standard; this can occur when the systems are subject to low irradiance.

In [34], an experimental analysis identified voltage waveform distortions in power grids due to the connection of PV systems using field measurements and simulations. The distortion characteristics of voltage waveforms that occur under different operating conditions were investigated. In addition to PV systems, the installed power would approach or even exceed the observed load from the point of common coupling (PCC), which could cause a significant occurrence of harmonics in the network.

In $[35,36]$, the authors considered the feasibility and importance of using simulation tools for studying the integration of photovoltaic system networks and the dimensioning of DGs to improve voltage and current profiles and reduce THDs.

OpenDSS is open-source software widely used in distribution power grid simulations. According to the software user's manual [37], the tool aims not only to perform load flow studies but also to analyse the distributed generation connected to the distribution grid. Its scope also includes probabilistic planning studies, solar photovoltaic and wind generator 
simulations, distribution state evaluations, and studies of harmonic and interharmonic distortions. Currently, OpenDSS performs all types of frequency domain verification.

The literature review has shown that to date, numerous studies related to the insertion of photovoltaic systems in distribution grids demonstrate the effects resulting from this process. However, there is a research gap regarding the high penetration of photovoltaic generation into distribution systems as they relate to the effects of harmonics and harmonic distortions, which we aimed to fill in this study. More importantly, a comparative analysis between the absence and presence of high photovoltaic system penetration was performed to evaluate the effects that harmonics may cause under this extreme situation. In other words, this study aimed to elucidate the effects produced by harmonics through the high penetration of photovoltaic systems in a distribution grid.

The main contributions of this article can be listed as follows: (a) careful analysis and evaluation of the influence and individual levels of harmonics on the behaviour of underground distribution systems, proposing that the high penetration of photovoltaic generators in these systems has a significant relationship with a higher incidence of odd harmonics of 3rd, 5th, and 7th orders through the $4.8 \mathrm{kV}$ underground cable distribution system (IEEE 37 Bus) to perform studies of THD levels on voltage and current; (b) proof that the effects of THD on voltage values do not produce significant impacts, even if current THD exceeds standards; (c) verification that the increase in harmonic level in the electric power system represents one of numerous factors that can influence the stability of a distribution grid, which is important for influencing research studies in this field; and (d) codification of the consequences of high photovoltaic system penetration on networks due to the generation of harmonics and, more specifically, an analysis of the implications on previous standards established within appropriate operational voltage limits and current limits.

The paper is structured as follows: Section 2 presents the systematic literature review methodology used; Section 3 describes the simulation setup and procedure, provides the results of the analysis of the paper, and discusses the results of the research. Finally, the last section offers conclusions and proposes future trends.

\section{Materials and Methods}

The increase in the level of harmonics in electrical power systems represents one of the numerous factors that can affect the operation of a distribution grid that supplies industrial, commercial, and residential services, which is important to leverage research studies in this field.

To obtain the results and answers to the questions presented in this work, descriptive research methods were used, quantitatively and bibliographically aimed at analysing the studies related to harmonics and power flow due to the high penetration of photovoltaic systems through a simulation in the proposed study system. In this context, the theme of this paper is inserted, which addresses theoretical studies and data collection activities obtained by simulation, enabling the calculation and analysis of the results of the effects produced by the high penetration of photovoltaic systems in an IEEE system 37 distribution bus.

The IEEE 37 bus Test Feeder is a standard distribution model developed by the IEEE Power \& Energy Society, located in CA, USA, with a nominal voltage of $4.8 \mathrm{kV}$ and a nominal capacity of $837 \mathrm{~kW}$, it has a complexity of loads and lines identical to that of a small town. For more information, such as cable length and impedances, visit [38].

The simulation was performed on the OpenDSS platform, which is used to estimate power distribution system losses and the level of harmonic distortions due to the high penetration of PV systems in the grid.

Two different scenarios were idealized to assess the impacts of the high penetration of photovoltaic generation in the distribution system. The first scenario was a simulation of the circuit without the addition of photovoltaic generation. The second was the simulation with the insertion of eight photovoltaic systems, consisting of one 2-MW system and 
seven 350-kW mini-systems. The choice of unit sizes for the one 2-MW and seven 350-kW photovoltaic systems established the capacity for large-scale penetration of photovoltaic systems to carry out the study.

When allocating the photovoltaic systems from the standpoint of an independent producer, considering the restrictions imposed by the concessionaire on the generation units to be connected to its system, it can be assumed by default that the units can be inserted into any node in the system. These nodes were chosen because they have no loads, and because the power flows passing through these nodes are almost zero, there are no significant losses to the system on its lines.

Under each scenario, the voltage variation, flux density, power circuit losses, and voltage and current harmonics were analysed with their respective percentages of total harmonic distortion (THD) and individual harmonic distortion (IHD). Table 1 shows the generation capacity of the PV systems added to the distribution system. Figure 1 shows the locations of the PV systems in IEEE 37.

Table 1. Location and generation capacity of PV systems in IEEE 37.

\begin{tabular}{cc}
\hline Location of PV Plants & Generation Capacity \\
\hline 737 & $2 \mathrm{MW}$ \\
740 & $350 \mathrm{~kW}$ \\
712 & $350 \mathrm{~kW}$ \\
718 & $350 \mathrm{~kW}$ \\
729 & $350 \mathrm{~kW}$ \\
730 & $350 \mathrm{~kW}$ \\
731 & $350 \mathrm{~kW}$ \\
720 & $350 \mathrm{~kW}$ \\
\hline
\end{tabular}

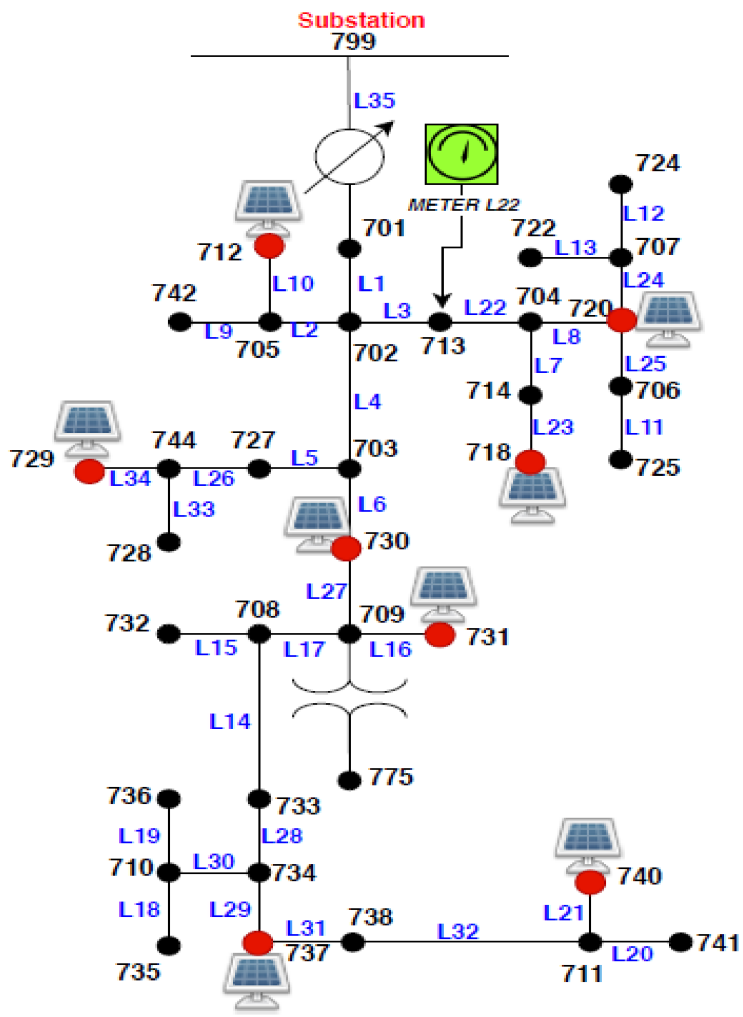

Figure 1. IEEE 37 bus test feeder layout with eight PV plant insertions.

The OpenDSS uses a PVSystem Element Model to simulate photovoltaic generation, which consists of a generator and photovoltaic inverter that have selected characteristics of the inverter typically convenient to perform impact studies in distribution systems [39]. 
The model considers the efficiency curve, maximum power point tracking (MPPT), and cut-in/cut-out as a function of DC voltage and reactive power control.

PV System Element: Figure 2 shows a block diagram of the PV system model available in the OpenDSS (PV system), which combines the characteristics of a PV system and an inverter into its structure, assuming that the inverter can quickly find the maximum power point tracking (MPPT).

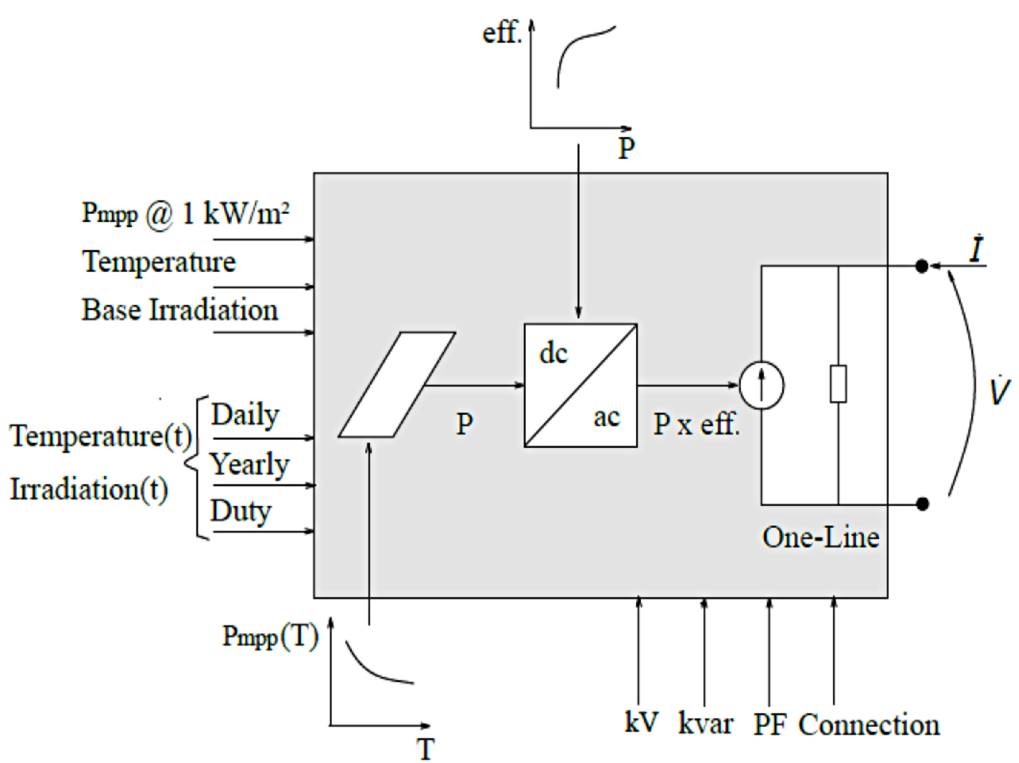

Figure 2. PV system model conceptual diagram.

The same model is capable of injecting active power (Pout) into the grid connection node. This is a function of irradiation, temperature, inverter efficiency, and rated power at the maximum power point (Pmpp), which is set to a selected temperature, usually $25^{\circ} \mathrm{C}$, and irradiation of $1 \mathrm{~kW} / \mathrm{m}^{2}$. The power provided by the PV to the system is given by Equation (1).

$$
\operatorname{Pout}(t)=P(t) \times \operatorname{eff}(P(t))
$$

where

$P(t)=\operatorname{Pmpp}\left(1 \mathrm{~kW} / \mathrm{m}^{2}\right) \times \operatorname{irrad}(\mathrm{t}) \times$ irradBase $\times \operatorname{Pmpp}(T(t))$

and

- $\quad \mathrm{P}(\mathrm{t})$ : output power of the PV array at a specific time, $t$

- $\operatorname{Pmpp}\left(1 \mathrm{~kW} / \mathrm{m}^{2}\right)$ : rated power at the maximum power point and a selected temperature

- $\quad \operatorname{irrad}(\mathrm{t})$ : per unit irradiation value at $\mathrm{t}$

- $\quad$ irradBase: base irradiation value for shape multipliers

- $\operatorname{Pmpp}(\mathrm{T}(\mathrm{t}))$ : Pmpp correction factor as a function of the temperature at $\mathrm{t}$

- $\quad$ eff $(P(t))$ : inverter efficiency for a given $P(t)$

Harmonic Analysis: The OpenDSS harmonics model, Mode = Harmonics, operates in the frequency domain and presents parameters for modelling nonlinear loads on the electrical grid. The loads are transformed into Norton equivalents, that is, the loads and other energy conversion elements are converted into current sources according to the schematic shown in Figure 3. 


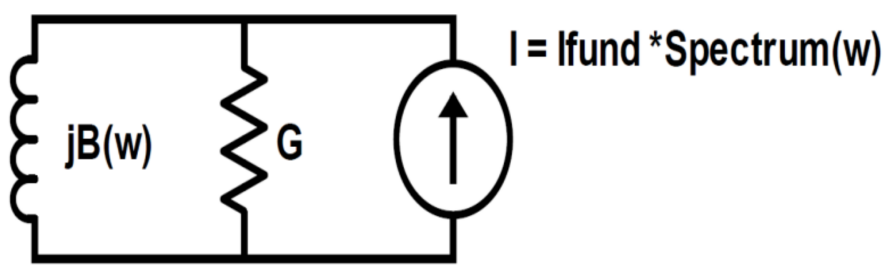

Figure 3. Definition of harmonic spectrum of current and voltage.

The study of harmonics in the OpenDSS comprises the resolution of network Equation (2) for each harmonic, where the system admittance matrix is constructed from representations of each component in the system.

$$
\mathrm{Im}=\mathrm{Ym} \times \mathrm{Vm} ; \mathrm{m}=1, \ldots, \mathrm{n}
$$

where

Im-the vector of source currents

Ym-nodal admittance matrix

$\mathrm{Vm}$-the vector of bus voltages

$\mathrm{m}$-harmonic order

For the modelling of harmonic components, it is necessary to create a new harmonic spectrum using the following line sequence of code based on Figure 4:

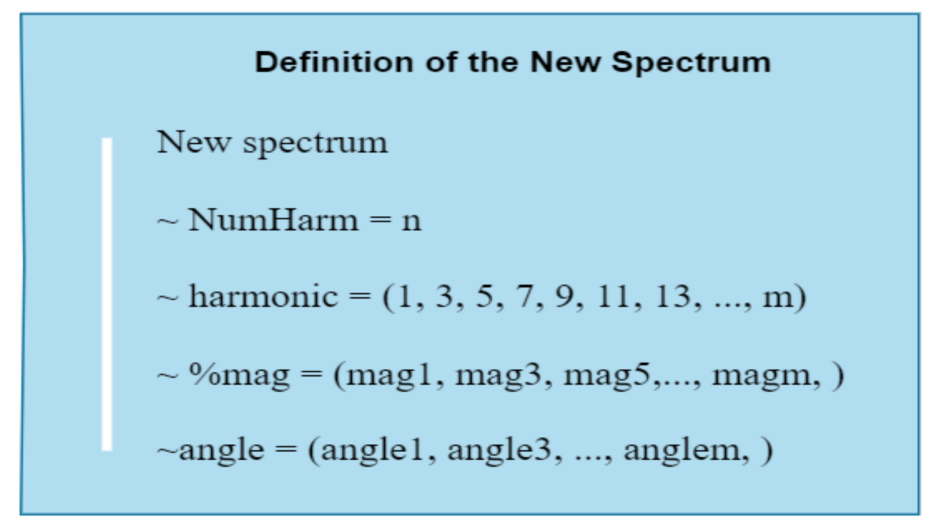

Figure 4. Definition of harmonic spectrum of current and voltage.

where the term "new spectrum" is the name chosen for the study of newly created harmonics. Additionally, as a reminder, the $\sim$ symbol is used to indicate continuity in the line of the code. A description of each command used is shown.

- New Spectrum - defines the specific name for the analysis

- NumHarm-specifies the number of harmonics in the spectrum

- Harmonic-specifies the harmonics of interest

- $\quad \%$ mag-percentage magnitude relative to fundamental value

- Angle-angle of harmonic components

The harmonic spectrum used in this work is typical of residences, being used in all loads for a quantity of 7 harmonics, from the fundamental frequency to the 13th order, presenting only the odd components, each with its specific magnitude and angle. This standard spectrum is based on [40].

\section{Results and Discussion}

\subsection{Case Study 1-System without Photovoltaic Generation}

The first scenario consisted of simulating the IEEE 37 system without the insertion of any type of photovoltaic generation. In the simulations, the temporal model of the loads 
was modified, which was chosen as Snapshot mode. This is the DEFAULT MODE that uses the power flow solution at the present load level, where the control mode is set to "static" and all control devices run following their time delays, starting primarily with the shorter ones.

A voltage monitor was placed on the L22 line of the circuit, which connected node 713, as shown in Figure 1. This line was chosen for voltage analysis because it is a line in which no photovoltaic generator would be inserted and because it was located in an intermediate position of the circuit. Therefore, all the energy flows would pass through this line and would be directed to the L22 meter. This monitor would remain present in all simulations of this work so that it was possible to observe the voltage changes and perform comparisons with other scenarios.

Figure 5 shows the power flow of the IEEE 37 circuit, and its feeder was connected to node 799 (see Figure 1). The distribution of power flow along the feeder can be seen through the thickness of the lines, in which the thickest lines have the highest concentration of power. It can be observed that the power intensity was higher near the conventional generation of the substation, highlighted by the flow density near node 799 (thick green line), and that this power intensity was directed to the heavier loads of the circuit.

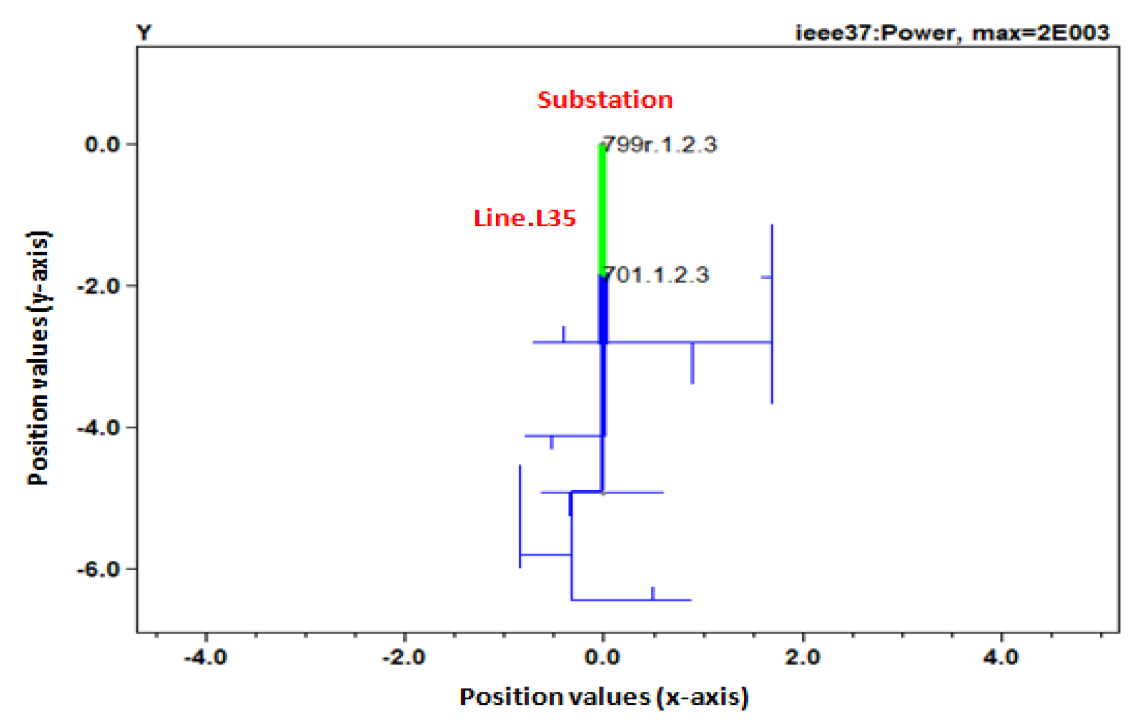

Figure 5. IEEE 37 circuit power flow distribution plot without PV insertion. For identification of nodes and lines, please see Figure 1 . The thicker line indicates more concentration of power, and the thin line indicates the opposite.

Table 2 presents the radial flow summary of the feeder (main source), located at node 799 of the IEEE 37 circuit, in terms of power without the presence of photovoltaic systems.

Table 2. Powers are delivered to the system by the substation generator (Node 799).

\begin{tabular}{cccccc}
\hline Element & Phase & kW & kvar & kVA & PF ${ }^{*}$ \\
\hline Transf.SUBXF & A & 731.8 & 630.8 & 966.1 & 0.76 \\
Transf.SUBXF & B & 836.0 & 357.4 & 909.2 & 0.92 \\
Transf.SUBXF & C & 1020.7 & 584.4 & 1176.1 & 0.87 \\
\hline TOTAL CONVENTIONAL GENERATION ELEMENT & & 2588.5 & 1572.6 & 3028.7 & 0.85 \\
\hline
\end{tabular}

${ }^{*} \mathrm{PF}=$ power factor.

Figure 6 shows the pu voltage as a function of the distance to the feeder. The $y$-axis shows the magnitude of voltages per unit, whereas the $x$-axis shows the distance from the substation to each bus and line, in kilometres. Measurements were made on line L1, which comprised the section between the end of nodes 701 and 702. The phases are identified 
by colours: phase $A$ black, phase $B$ red, and phase $C$ blue. It was noted that the phase voltages were within the range determined in $\mathrm{pu}(0.93$ to 1.05$)$ established by the American National Standards Institute (ANSI) [26]. Therefore, the appropriate voltage limit was not exceeded $(0.95 \leq \mathrm{v} \leq 1.05 \mathrm{pu})$, according to Table 3 .

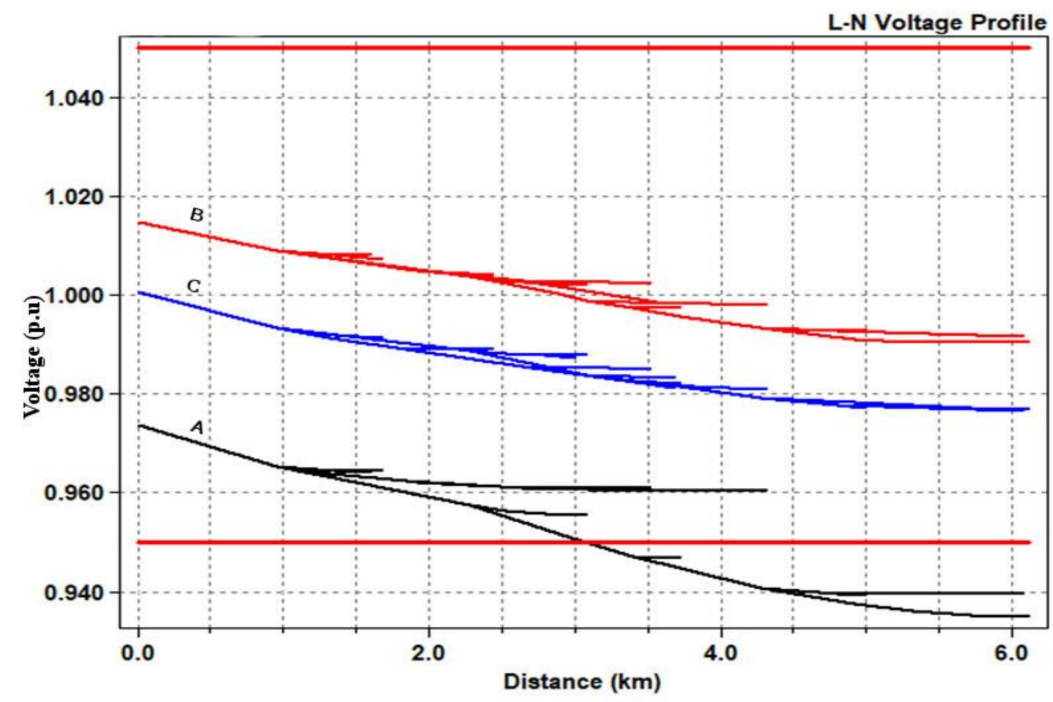

Figure 6. Voltage profile from the 37 bus feeder without PV.

Table 3. Voltage rating range-nominal voltage connection points from $1 \mathrm{kV}$ to $69 \mathrm{kV}$ (ANSI C84.12006).

\begin{tabular}{cc}
\hline Attendance Voltage (AT) & Range of Variation in pu \\
\hline Adequate & $0.95 \leq \mathrm{v} \leq 1.05 \mathrm{pu}$ \\
Poor & $0.90 \leq \mathrm{v}<0.95 \mathrm{pu}$ \\
Critical & $<0.90 \mathrm{pu}$ or $>1.05 \mathrm{pu}$ \\
\hline
\end{tabular}

The loss density of this system is shown in Figure 7. The thickness of the line relates to the system losses.

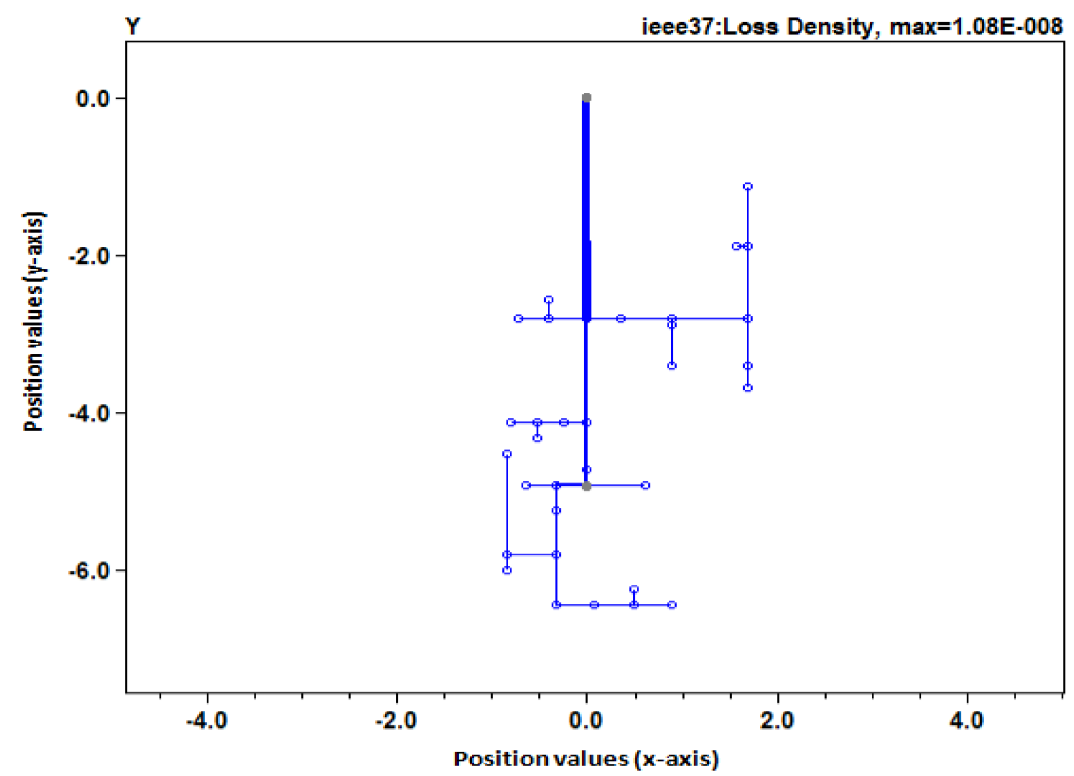

Figure 7. Loss density plot of the IEEE 37 circuit without PV insertion. For identification of nodes and lines, please see Figure 1. The thicker line indicates more losses, and the thin line indicates the opposite. 
A thicker line indicates more losses, and a thin line indicates the opposite. It is possible to note that the losses were directly associated with the position of the generator and the distance travelled by the power to reach the loads.

The total losses were $152.3 \mathrm{~kW}$, approximately $6.25 \%$ of the active load of the system (according to Table 4). The most significant losses were in L1 (701-702), L4 (702-703), L6 (703-730), and L35 (799-701). They were examples of the loss of the capacity of the system, which could reach approximately $50 \mathrm{~kW}$. However, it is worth mentioning that there were lines in which losses were derisory, as one can observe in lines L2 (702-705), L3 (702-713), L5 (703-727), L7 (704-714), L8 (704-720), L9 (705-742), L10 (705-712), and L11 (706-725), for example.

Table 4. Losses in the lines of the IEEE 37 circuit without GD.

\begin{tabular}{|c|c|c|c|}
\hline Element & Losses (kW) & \%Power & (kvar) \\
\hline Transformer.SUBXF & 75.44 & 2.91 & 301.77 \\
\hline Transformer.XFM1 & 0.00 & 0.00 & 0.00 \\
\hline Line.L1 & 10.96 & 0.60 & 10.81 \\
\hline Line.L2 & 0.25 & 0.14 & -0.02 \\
\hline Line.L3 & 0.92 & 0.17 & 0.41 \\
\hline Line.L4 & 5.93 & 0.53 & 5.41 \\
\hline Line.L5 & 0.28 & 0.11 & 0.03 \\
\hline Line.L6 & 4.08 & 0.48 & 2.20 \\
\hline Line.L7 & 0.03 & 0.02 & -0.01 \\
\hline Line.L8 & 0.98 & 0.30 & 0.30 \\
\hline Line.L9 & 0.08 & 0.08 & -0.06 \\
\hline Line.L10 & 0.06 & 0.07 & -0.04 \\
\hline Line.L11 & 0.02 & 0.04 & -0.07 \\
\hline Line.L12 & 0.04 & 0.10 & -0.18 \\
\hline Line.L13 & 0.08 & 0.05 & -0.00 \\
\hline Line.L14 & 1.36 & 0.21 & 0.68 \\
\hline Line.L15 & 0.02 & 0.05 & -0.07 \\
\hline Line.L16 & 0.07 & 0.08 & -0.15 \\
\hline Line.L17 & 1.54 & 0.22 & 0.80 \\
\hline Line.L18 & 0.05 & 0.06 & -0.03 \\
\hline Line.L19 & 0.07 & 0.17 & -0.30 \\
\hline Line.L20 & 0.01 & 0.03 & -0.12 \\
\hline Line.L21 & 0.05 & 0.06 & -0.03 \\
\hline Line.L22 & 0.98 & 0.22 & 0.38 \\
\hline Line.L23 & 0.11 & 0.14 & -0.10 \\
\hline Line.L24 & 1.06 & 0.52 & 0.09 \\
\hline Line.L25 & 0.02 & 0.04 & -0.18 \\
\hline Line.L26 & 0.12 & 0.06 & -0.02 \\
\hline Line.L27 & 1.11 & 0.14 & 0.58 \\
\hline Line.L28 & 1.78 & 0.32 & 0.87 \\
\hline Line.L29 & 1.14 & 0.30 & 0.45 \\
\hline Line.L30 & 0.19 & 0.15 & -0.06 \\
\hline Line.L31 & 0.29 & 0.11 & 0.05 \\
\hline Line.L32 & 0.12 & 0.09 & -0.05 \\
\hline Line.L33 & 0.05 & 0.04 & -0.03 \\
\hline Line.L34 & 0.02 & 0.04 & -0.07 \\
\hline Line.L35 & 28.44 & 1.14 & 26.87 \\
\hline Transformer.REG1A & 7.61 & 0.98 & 19.03 \\
\hline Transformer.REG1C & 6.97 & 0.40 & 17.44 \\
\hline Line.JUMPER & 0.00 & 0.00 & 0.00 \\
\hline \multicolumn{4}{|c|}{$\begin{array}{c}\text { Line losses }=62.3 \mathrm{~kW} \\
\text { Transformer losses }=90.0 \mathrm{~kW} \\
\text { Total losses }=152.3 \mathrm{~kW} \\
\text { Total load power }=2436.0 \mathrm{~kW} \\
\text { Percent losses for circuit }=6.25 \%\end{array}$} \\
\hline
\end{tabular}


In Table 4 , the direction of the power flow is indicated by the positive or negative signal considering the extreme of each line: for example, considering the end of the L1 line (node 701) for line L2 (node 702), there was 10.8134 kvar, that is, if the result was positive, then it arrived from line L1 to line L2. The same occurred with the value $-0.0198301 \mathrm{kvar}$ from the end of line L2 (node 702) to line L9 (node 705); if the result was negative, then it effectively arrived from line L9 to line L2.

Figure 8 graphically emphasises the losses caused in the IEEE 37 system without the insertion of photovoltaic systems.

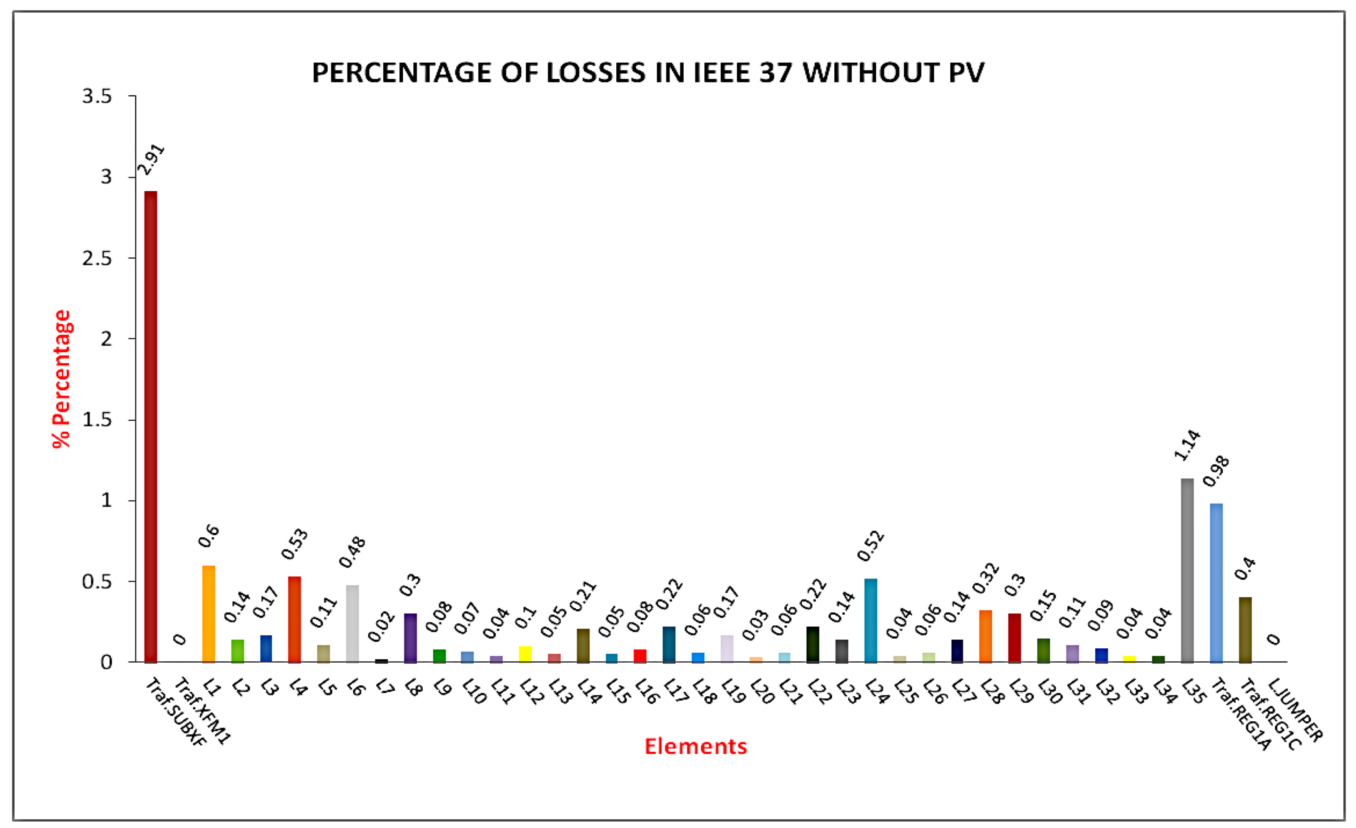

Figure 8. Percentage of losses in the IEEE 37 bus without PV.

\subsection{Case Study 2-System with Photovoltaic Generation}

This scenario showed the simulation with a 2-MW PV system connected to node 737 of the IEEE 37 circuit and seven 350-kW PV systems connected to nodes 712, 718, 720, 729, 730,731 , and 740 .

These nodes were chosen to connect the PV systems once the independent producer complied with the restriction rules imposed by the concessionaire (for example, a maximum rated power). In this case, it could be assumed by default that the units could be inserted into any node in the system.

The graphs in Figure 9 present the installed solar systems taking into consideration the irradiance curves on the photovoltaic panel for $24 \mathrm{~h}$, the temperature that the photovoltaic panel reached during the day, nominal power as a function of temperature, and solar panel efficiency.

The simulation with eight photovoltaic systems inserted in the IEEE 37 bus distribution system was done in Snapshot mode. Therefore, the respective spectra were assigned to the photovoltaic elements of the system. These included a property for energy conversion elements (PCElements, such as loads, capacitors, photovoltaic systems, storage, etc.) and not for power supply elements (PDElements, such as lines, transformers, etc.) [37]. The simulation was carried out in the harmonic mode of the OpenDSS, with spectra being assigned to each PV system according to the structure shown in Figure 4. The spectra used by the OpenDSS present a quantity of seven harmonics, from the fundamental frequency to the 13th order. Only the odd components were used, with their specific magnitudes and angles as follows.

New Spectrum.pv_harmonics numharm $=7$

harmonic $=(1,3,5,7,9,11,13)$ 
$\%$ mag $=(100,0.69,0.63,0.56,0.19,0.07,0.17)$

angle $=(0,128,207,10,356,329,304)$

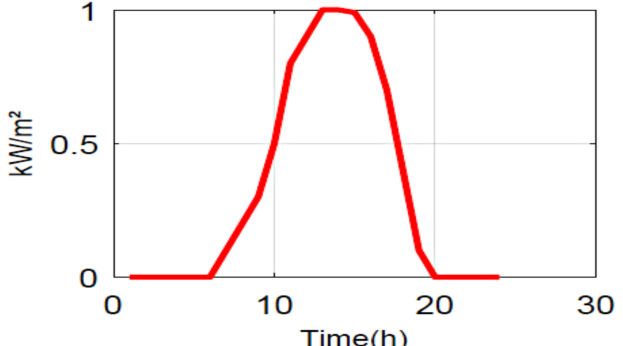

(a) Irradiance on the photovoltaic panel

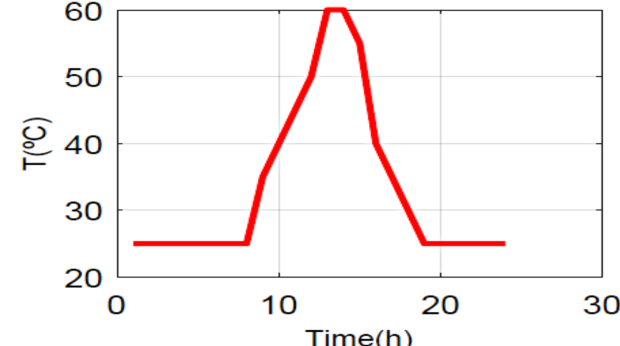

(b) Panel temperature

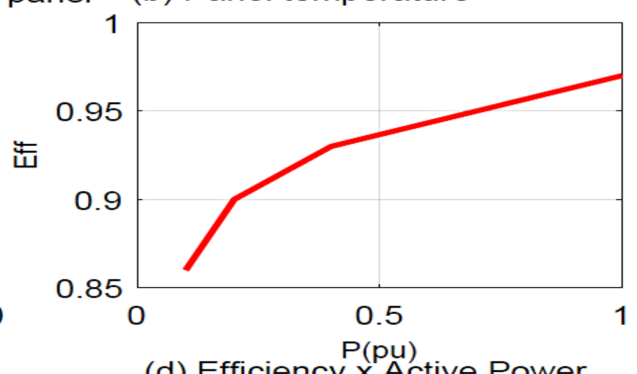

(d) Efficiency $\times$ Active Power

(c) $\mathrm{Pmp} \times \mathrm{T}^{\mathrm{T}}\left({ }^{\circ} \mathrm{C}\right)$

Figure 9. Curves of the photovoltaic panels.

In the OpenDSS, the monitors were placed on nodes 712, 718, 720, 729, 730, 731, 737, and 740 to observe system losses and harmonic levels, evaluating individual (THDi) and total harmonic distortions (THDv). These measured values allowed us to identify if the levels were outside the standard harmonic spectrum range considered by the IEEE519 standard [41]. For more details on how the OpenDSS measures and computes the harmonics, see [37].

These measured values allowed us to identify whether the levels had changed outside the range considered by the established standard. Figure 10 shows the power flow of the circuit with the photovoltaic systems inserted in the IEEE 37 bus distribution system. One can note that it was more balanced than the circuit in Figure 5, according to the thickness of the lines. In this scenario, the circuit did not need all the energy from the main feeder. This occurred because the photovoltaic generators installed in the system guaranteed the supply of the necessary energy for the loads near them on both sides of the circuit.

If we take into account that the PV power was inserted into a system with $2588.5 \mathrm{~kW}$, the PV penetration was $172 \%$. The capacity of the PV power plants $(2 \mathrm{MW}$ and $7 \times 350 \mathrm{~kW})$ represented $63 \%$ of overall power generation.

It should be noted that the power flow from the photovoltaic power plants was slightly thicker than from the power plant at node 799. This occurred because the photovoltaic generation was larger than the conventional energy generation of the system. According to Table 5, the total power delivered by the solar panels was $4224.2 \mathrm{~kW}$, while the feeder provided approximately $1574.9 \mathrm{~kW}$ to the system. Photovoltaic generation was equivalent to $72.8 \%$ of the total active power delivered to the system. 


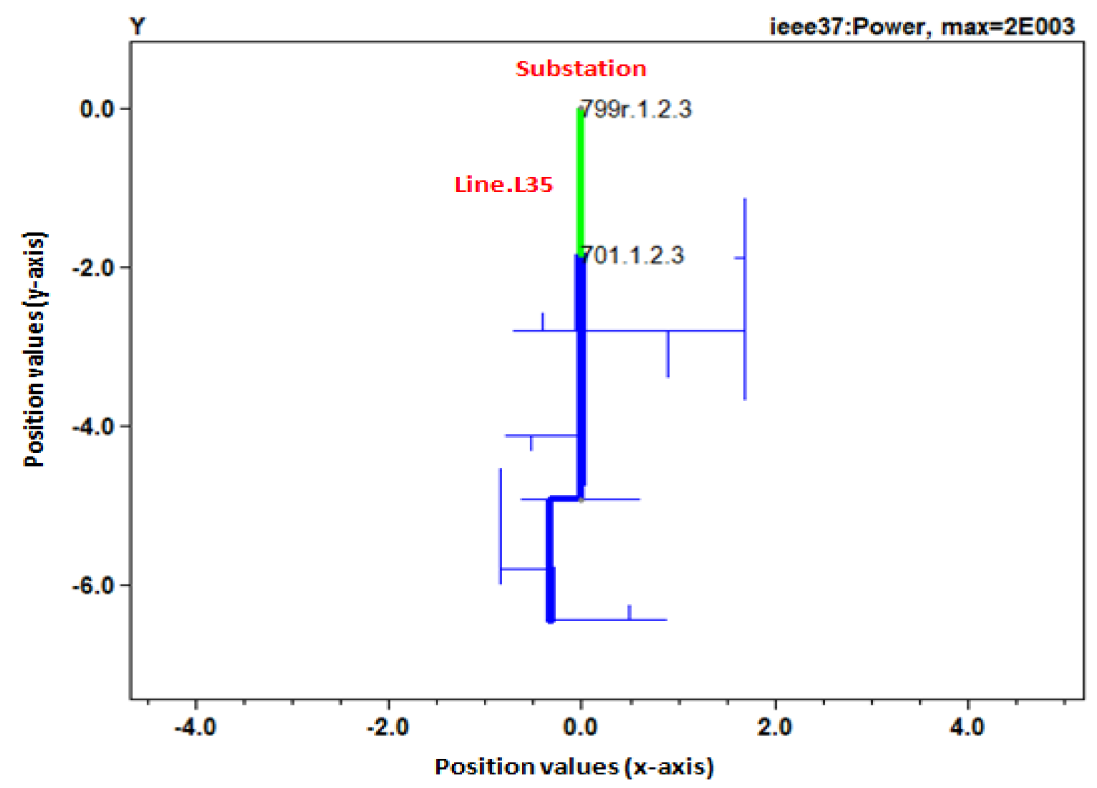

Figure 10. IEEE 37 circuit power flow distribution plot with PV insertion. For identification of nodes and lines, please see Figure 1. The thicker line indicates more concentration of power, and the thin line indicates the opposite.

Table 5. Power delivered to the system by substation generators (node 799) and photovoltaic systems.

\begin{tabular}{|c|c|c|c|c|c|}
\hline Element & Phase & $\mathbf{k W}$ & kvar & kVA & PF \\
\hline Transformer.SUBXF & A & 656.5 & 722.6 & 976.3 & 0.67 \\
\hline Transformer.SUBXF & $\mathrm{B}$ & 628.6 & 315.3 & 703.2 & 0.89 \\
\hline Transformer.SUBXF & $\mathrm{C}$ & 289.8 & 543.1 & 615.6 & 0.47 \\
\hline Total conventional generation & & 1574.9 & 1581.0 & 2231.6 & 0.70 \\
\hline PVSystem.PV1 & A & 110.7 & 0.0 & 110.7 & 1 \\
\hline PVSystem.PV1 & $\mathrm{B}$ & 110.7 & 0.0 & 110.7 & 1 \\
\hline PVSystem.PV1 & $\mathrm{C}$ & 110.8 & 0.0 & 110.8 & 1 \\
\hline Total & & 332.2 & 0.0 & 332.2 & 1 \\
\hline PVSystem.PV2 & A & 632.8 & 0.0 & 632.8 & 1 \\
\hline PVSystem.PV2 & $\mathrm{B}$ & 632.8 & 0.0 & 632.8 & 1 \\
\hline PVSystem.PV2 & $\mathrm{C}$ & 632.9 & 0.0 & 632.9 & 1 \\
\hline Total & & 1898.5 & 0.0 & 1898.5 & 1 \\
\hline PVSystem.PV3 & A & 110.7 & 0.0 & 110.7 & 1 \\
\hline PVSystem.PV3 & $\mathrm{B}$ & 110.8 & 0.0 & 110.8 & 1 \\
\hline PVSystem.PV3 & $\mathrm{C}$ & 110.8 & 0.0 & 110.8 & 1 \\
\hline Total & & 332.3 & 0.0 & 332.3 & 1 \\
\hline PVSystem.PV4 & A & 110.7 & 0.0 & 110.7 & 1 \\
\hline PVSystem.PV4 & $\mathrm{B}$ & 110.7 & 0.0 & 110.7 & 1 \\
\hline PVSystem.PV4 & $\mathrm{C}$ & 110.8 & 0.0 & 110.8 & 1 \\
\hline Total & & 332.2 & 0.0 & 332.2 & 1 \\
\hline PVSystem.PV5 & $\mathrm{A}$ & 110.7 & 0.0 & 110.7 & 1 \\
\hline PVSystem.PV5 & $\mathrm{B}$ & 110.7 & 0.0 & 110.7 & 1 \\
\hline PVSystem.PV5 & $\mathrm{C}$ & 110.8 & 0.0 & 110.8 & 1 \\
\hline Total & & 332.2 & 0.0 & 332.2 & 1 \\
\hline
\end{tabular}


Table 5. Cont.

\begin{tabular}{cccccc}
\hline Element & Phase & $\mathbf{k W}$ & $\mathbf{k v a r}$ & $\mathbf{k V A}$ & $\mathbf{P F}$ \\
\hline PVSystem.PV6 & $\mathrm{A}$ & 110.7 & 0.0 & 110.7 & 1 \\
PVSystem.PV6 & $\mathrm{B}$ & 110.8 & 0.0 & 110.8 & 1 \\
PVSystem.PV6 & $\mathrm{C}$ & 110.8 & 0.0 & 110.8 & 1 \\
\hline Total & & 332.3 & 0.0 & 332.3 & 1 \\
\hline PVSystem.PV7 & $\mathrm{A}$ & 110.7 & 0.0 & 110.7 & 1 \\
PVSystem.PV7 & $\mathrm{B}$ & 110.7 & 0.0 & 110.7 & 1 \\
PVSystem.PV7 & $\mathrm{C}$ & 110.8 & 0.0 & 110.8 & 1 \\
\hline Total & & 332.2 & 0.0 & 332.2 & 1 \\
\hline PVSystem.PV8 & $\mathrm{A}$ & 110.7 & 0.0 & 110.7 & 1 \\
PVSystem.PV8 & $\mathrm{B}$ & 110.8 & 0.0 & 110.8 & 1 \\
PVSystem.PV8 & $\mathrm{C}$ & 110.8 & 0.0 & 110.8 & 1 \\
\hline Total & & 332.3 & 0.0 & 332.3 & 1 \\
\hline Total photovoltaic generation & & 4224.2 & 0.0 & 4224.2 & 1 \\
\hline Total delivered & & 5799.1 & 1581.0 & 6010.8 & 0.89 \\
\hline
\end{tabular}

The circuit power factor in the absence of photovoltaic generation was 0.85 . The power factor for the scenario with the insertion of photovoltaic systems was 0.70 for conventional generation. The impacts of the reduction on the power factor were significant because of the introduction of PV systems; there was a decrease in the demand for active energy and variations in the reactive energy demand of the load. This is because there was an increase in losses and the reactive power of the system, as can be observed in line L29 (node737), which indicates losses that go beyond 7 kvar (Table 6).

Table 6. Losses in the lines of the IEEE 37 circuit with GD.

\begin{tabular}{cccr}
\hline Element & Losses $(\mathbf{k W})$ & \% Power & (kvar) \\
\hline Transformer.SUBXF & 43.86 & 2.79 & 175.45 \\
Transformer.XFM1 & 0.00 & 0.00 & 0.00 \\
Line.L1 & 15.13 & 0.67 & 15.31 \\
Line.L2 & 0.19 & 0.13 & -0.05 \\
Line.L3 & 0.24 & 0.21 & 0.03 \\
Line.L4 & 15.09 & 0.75 & 15.10 \\
Line.L5 & 0.09 & 0.12 & -0.04 \\
Line.L6 & 16.41 & 0.84 & 8.83 \\
Line.L7 & 0.06 & 0.03 & -0.00 \\
Line.L8 & 0.38 & 17.10 & -0.04 \\
Line.L9 & 0.08 & 0.08 & -0.06 \\
Line.L10 & 0.22 & 0.09 & 0.00 \\
Line.L11 & 0.02 & 0.04 & -0.07 \\
Line.L12 & 0.10 & -0.19 \\
Line.L13 & 0.04 & 0.05 & -0.01 \\
Line.L14 & 0.08 & 0.35 & 2.84 \\
Line.L15 & 5.38 & 0.04 & -0.08 \\
Line.L16 & 0.02 & 0.11 & -0.05 \\
Line.L17 & 0.26 & 0.35 & 2.72 \\
Line.L18 & 5.18 & 0.05 & -0.04 \\
Line.L19 & 0.04 & 0.17 & -0.34 \\
Line.L20 & 0.08 & 0.03 & -0.14 \\
Line.L21 & 0.01 & 0.07 & -0.00 \\
Line.L22 & 0.18 & 0.19 & 0.06 \\
Line.L23 & 0.38 & 0.19 & 0.00 \\
\hline
\end{tabular}


Table 6. Cont.

\begin{tabular}{cccr}
\hline Element & Losses $\mathbf{( k W )}$ & \% Power & (kvar) \\
\hline Line.L24 & 1.06 & 0.51 & 0.08 \\
Line.L25 & 0.02 & 0.04 & -0.19 \\
Line.L26 & 0.06 & 0.05 & -0.06 \\
Line.L27 & 4.21 & 0.24 & 2.26 \\
Line.L28 & 10.17 & 0.62 & 5.40 \\
Line.L29 & 13.79 & 0.76 & 7.44 \\
Line.L30 & 0.18 & 0.14 & -0.09 \\
Line.L31 & 0.11 & 0.14 & -0.08 \\
Line.L32 & 0.17 & 0.08 & -0.05 \\
Line.L33 & 0.05 & 0.04 & -0.04 \\
Line.L34 & 0.30 & 0.11 & 0.02 \\
Line.L35 & 15.83 & 0.97 & 15.67 \\
Transformer.REG1A & 4.53 & 0.35 & 11.32 \\
Transformer.REG1C & 1.57 & 0.41 & 3.92 \\
Line.JUMPER & 0.00 & 0.00 & 0.00 \\
Transformer.PV_UP1 & 0.21 & 0.06 & 3.02 \\
Transformer.PV_UP2 & 5.26 & 0.28 & 75.60 \\
Transformer.PV_UP3 & 0.21 & 0.06 & 3.08 \\
Transformer.PV_UP4 & 0.21 & 0.06 & 3.05 \\
Transformer.PV_UP5 & 0.20 & 0.06 & 2.90 \\
Transformer.PV_UP6 & 0.21 & 0.06 & 3.07 \\
Transformer.PV_UP7 & 0.21 & 0.06 & 3.00 \\
Transformer.PV_UP8 & 0.21 & 0.06 & 3.07 \\
\hline & Line losses = 106.0 kW & \\
\hline & Transformer losses $=56.7 \mathrm{~kW}$ & \\
\hline & Total losses = 162.7 $\mathrm{kW}$ & \\
\hline
\end{tabular}

The main generation of the system began to deliver a larger amount of reactive power after the insertion of the photovoltaic energy systems, going from $1572.6 \mathrm{kvar}$ to $1581 \mathrm{kvar}$. This was related to the fact that photovoltaic systems, when introduced in the distribution system, cause a surplus of reactive power, due to a smaller amount of active energy needed from the primary source, causing a decrease in the power factor of the system.

A low power factor shows that the energy was being misused and could bring risks in terms of energy losses and reduction in the use of the capacity of the transformers. One of the basic measures to correct the low power factor would be to install a capacitor bank when necessary.

Figure 11 shows an advantage due to the insertion of photovoltaic generation in this system; energy distribution in this scenario was carried out in a more uniform and balanced way, coming from both sides of the system, which influenced the power demand factor for the concessionaire regarding the system.

By comparing the loss density of the IEEE 37 circuit with the absence of photovoltaic systems and the presence of eight photovoltaic systems inserted in the distribution system, Figures 7 and 11 show that the results of the total losses presented under the two scenarios were $6.25 \%$ (Table 4 ) for the circuit without the photovoltaic systems and $6.54 \%$ (Table 6) for the circuit with the photovoltaic system, resulting in a small increase of $0.29 \%$ in losses. In this situation, losses were also better distributed by the system, and lines that previously did not compute losses, or had small values, began to register higher densities, which could be observed in line L6 connected between nodes (703 and 730), line L28 (733 and 734), and line L29 (734 and 737), which previously had insignificant active power losses and then showed losses of $16.41 \mathrm{~kW}, 10.17 \mathrm{~kW}$, and $13.79 \mathrm{~kW}$, according to Table 6 . 


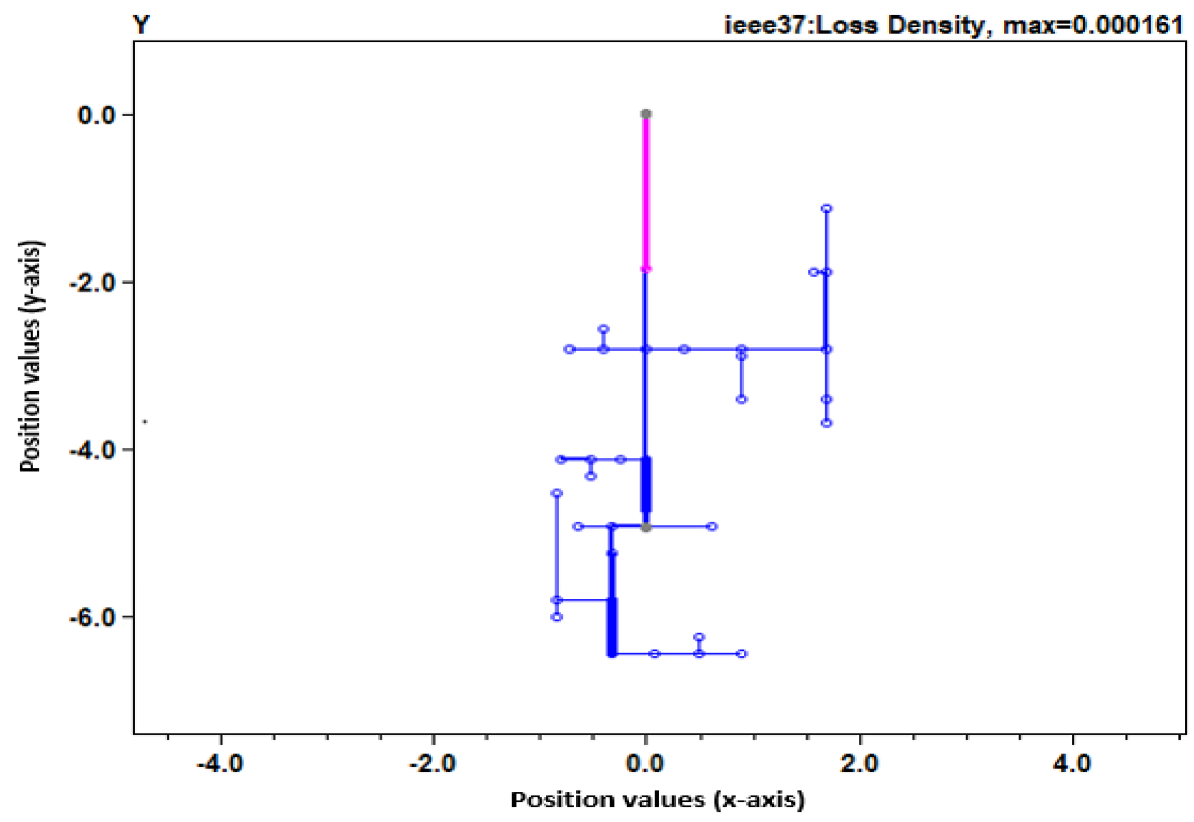

Figure 11. Loss density plot of the IEEE 37 circuit with PV insertion. For identification of nodes and lines, please see Figure 1. The thicker line indicates more losses, and the thin line indicates the opposite.

The losses reached a total of $162.7 \mathrm{~kW}$ of active power, $56.7 \mathrm{~kW}$ in the transformers that were connected to the circuits with the photovoltaic generation, and 364.9 kvar of reactive loss in the elements, and the value of losses without photovoltaic generation was 389.8 kvar. Despite the increase in losses concerning reactive power, there was also an increase of approximately $6.39 \%$ in the total losses of active power on the lines and transformers of the system $(162.7 \mathrm{~kW})$ when compared to the circuit without the presence of photovoltaic systems $(152.3 \mathrm{~kW})$. However, it is possible to observe in Tables 4 and 6 that the active power losses of the lines specifically increased, while they decreased for the substation transformer. This reduction of active power loss specifically for the conventional generator of the substation occurred because the feeder was poorly required, and the power distribution was more homogeneous in the circuit as a function of the photovoltaic generation, thus causing a reduction of the energy demand to be released to the system by the transformer at the substation. The system's active power losses reached only $2.043 \%$ of the total active system load. Figure 12 highlights the losses caused in the IEEE 37 system with the insertion of photovoltaic systems, according to Table 6.

A unique aspect arising from the introduction of photovoltaic systems in electrical networks is the system voltage, which undergoes alteration. Figure 6 shows the voltage profile of the system without the presence of photovoltaic generation systems, while Figure 13 shows that of the system with the insertion of photovoltaic generation systems.

The voltage monitor placed on line L22 registered higher voltages than those previously detected when there was no photovoltaic generation, which is perceived due to increased black and blue colour curves, revealing the influence that the insertion of photovoltaic generation may have on the circuit.

Figure 13 shows the voltage profile in pu as a function of the distance of the feeder through the meter (energy meter), installed on the first line L1, where the $x$-axis shows the magnitude of the voltages per unit, while the $y$-axis shows the distance of the substation from each node and line in kilometres.

The voltage profile model when photovoltaic systems were inserted showed that the voltage levels of phases $A$ and $C$ were slightly higher than the values presented when photovoltaic systems were not present in the electrical distribution system. 


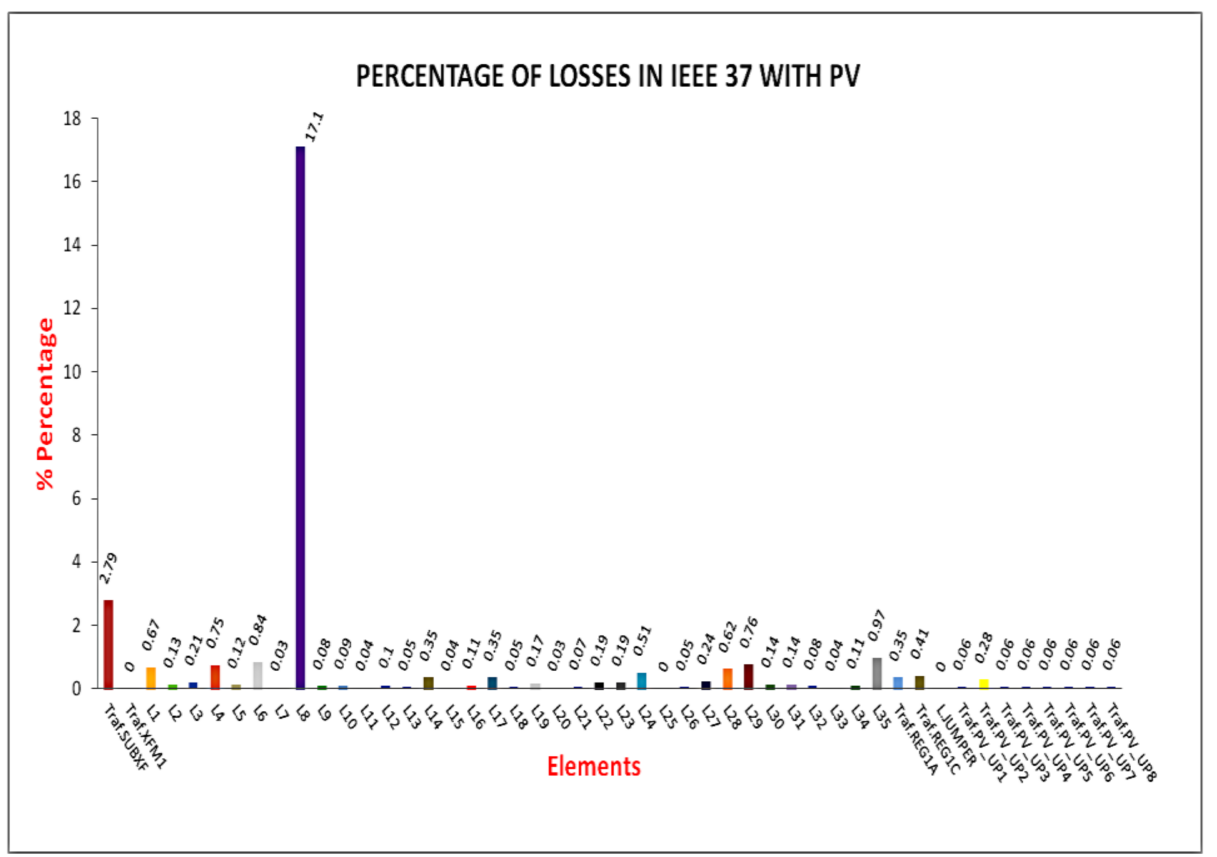

Figure 12. Percentage of losses in IEEE 37 bus with PV.

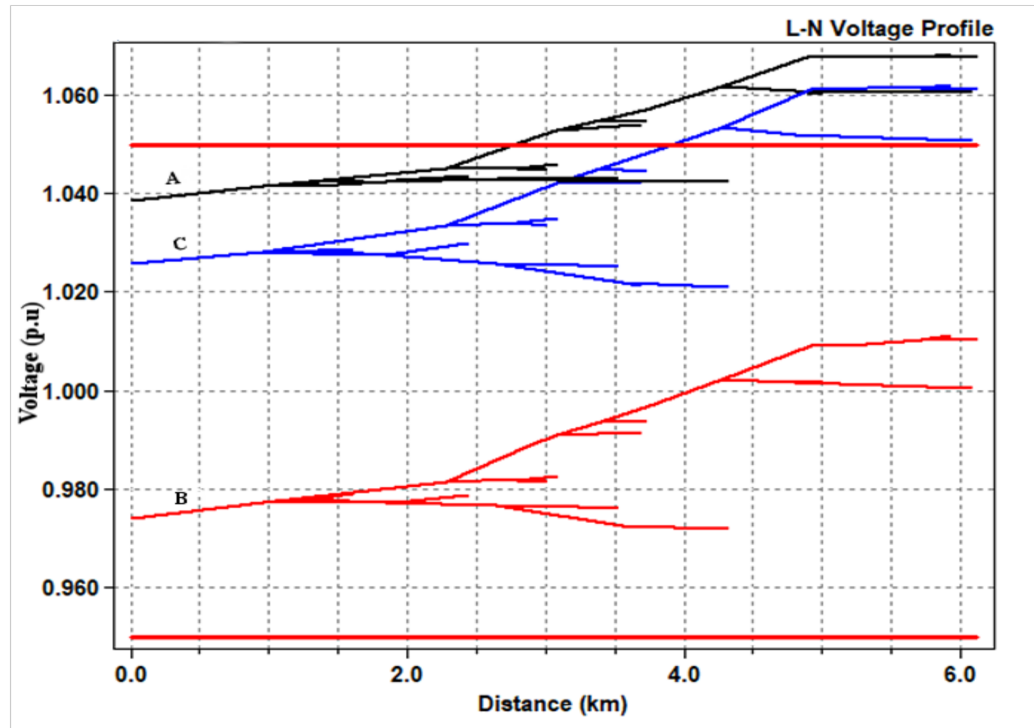

Figure 13. Voltage profile from the 37 bus feeder with PV insertion.

\subsection{Analysis of Harmonic Voltages (IHDV and THDV)}

The synthesis of the values of individual voltage distortions obtained with the simulation and monitoring for the frequency spectra corresponding to the harmonics of the 3rd, 5th, 7th, 9th, 11th, and 13th orders resulting from the insertion of the PV systems is shown in Figure 14. 


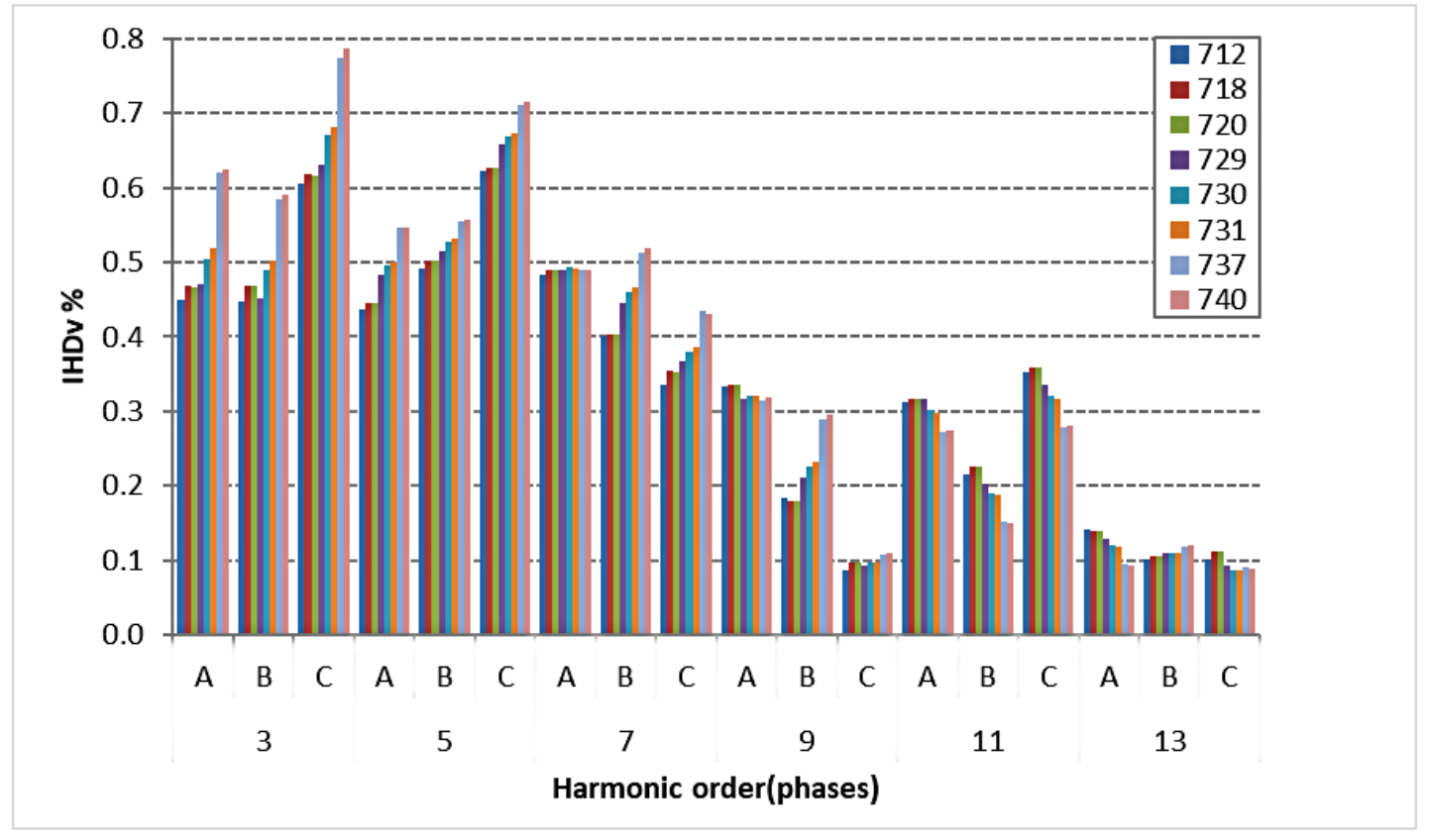

Figure 14. IHDv spectrum at IEEE 37 bus PV systems.

The values of the total harmonic voltage distortions calculated by Equation (3) in phases A, B, and C related to nodes 712, 718, 720, 729, 730, 731, 737, and 740 are represented in Figure 15.

$$
T H D v=\sqrt{\sum_{h=2}^{h=m a ́ x} \frac{v_{h}^{2}}{v_{1}^{2}}} \cdot 100 \%
$$

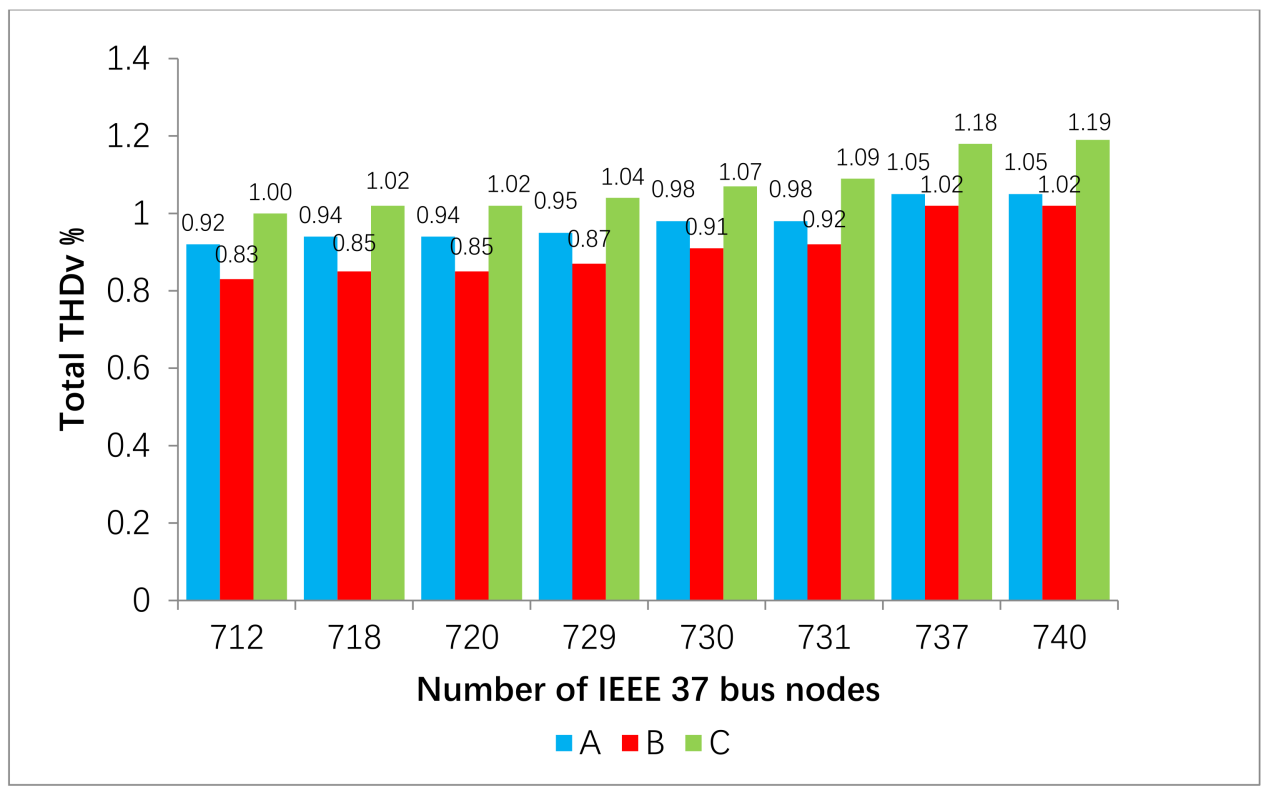

Figure 15. Total THDv spectrum per phase in IEEE 37 bus PV systems.

Table 7 shows that the IEEE 519 harmonic voltage limited the overall harmonic distortion of the voltage supplied by the utility. 
Table 7. Voltage distortion limits according to the IEEE 519 standard *.

\begin{tabular}{ccc}
\hline $\begin{array}{c}\text { Bus Voltage } \\
\text { at PCC }\end{array}$ & $\begin{array}{c}\text { Individual } \\
\text { Harmonic (\%) }\end{array}$ & $\begin{array}{c}\text { Total Harmonic } \\
\text { Distortion THD (\%) }\end{array}$ \\
\hline $\mathrm{V} \leq 1.0 \mathrm{kV}$ & 5.0 & 8.0 \\
$1 \mathrm{kV}<\mathrm{V} \leq 69 \mathrm{kV}$ & 3.0 & 5.0 \\
$69 \mathrm{kV}<\mathrm{V} \leq 161 \mathrm{kV}$ & 1.5 & 2.5 \\
$161 \mathrm{kV}<\mathrm{V}$ & 1.0 & 1.5 \\
\hline
\end{tabular}

* Note: High-voltage systems can have up to $2 \%$ THD where the cause is an HVDC terminal that will attenuate by the time it is tapped for a user.

For the analysis of voltage distortions at the eight insertion points of photovoltaic systems, ANSI resolution C84.1-2006 in [40] established that the effective voltage values can range from $0.93 \mathrm{pu}(2576 \mathrm{~V})$ to $1.05 \mathrm{pu}(2908 \mathrm{~V})$.

According to Figures 14 and 15, ANSI C84.1-2006 (Table 3) and IEEE 519: 2014 (Table 7), the voltage level, IHDv, and THDv levels met the standards for points 712, 718, 720, 729, 730, and 731, but points 737 and 740 were increased due to the injection of PV energy, violating the standard limits in [40] in phases $A$ and $C$, with variations in values that can be considered negligible concerning the standard value of $1.05 \mathrm{pu}$.

Figure 16 shows the nominal voltage values in each phase obtained at the connection points.

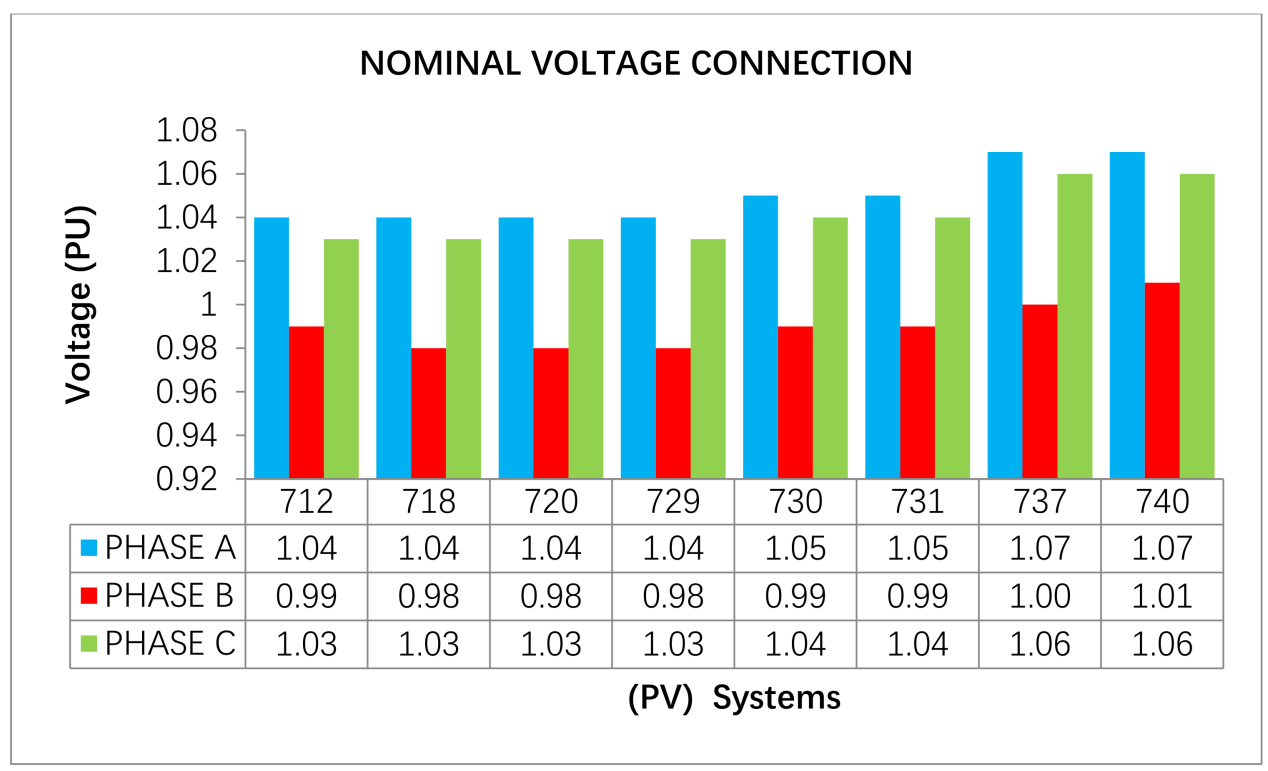

Figure 16. Nominal voltage at connection points.

Concerning the measurements of voltage distortions at measuring point 737 to the detriment of the resolution of the ANSI at C84.1-2006, the voltage values ranged from $1.07 \mathrm{pu}$ (phase A), $1.0 \mathrm{pu}$ (phase B), to $1.06 \mathrm{pu}$ (phase C). In this particular case, a small margin of difference was observed in phases $\mathrm{A}$ and $\mathrm{C}$, approximately the range considered suitable to be $0.93 \mathrm{pu}(2576 \mathrm{~V})$ to $1.05 \mathrm{pu}(2908 \mathrm{~V})$, which was outside this range.

The harmonic measurements of the nominal voltage for the distortion were within limits established by the standard. The total harmonic distortion was $1.05 \%$ for phase A, $1.02 \%$ for phase B, and $1.18 \%$ for phase C. The highest amplitude of IHDv in the three phases was the 3 rd phase, and the harmonics with the highest harmonic voltage distortion values were the $3 \mathrm{rd}$, 5 th, and 7 th phases. The 5 th and 7 th percentiles reached values of $0.71 \%$, and $0.51 \%$, and 3 rd percentiles reached $0.77 \%$. The maximum allowed value was $3 \%$. 
Based on the evaluation performed, measurement point 737 complied with the standards and resolutions of the harmonics in [41], but concerning the voltage limits in [40], a small extrapolation in phases $\mathrm{A}$ and $\mathrm{C}$ was observed.

By analysing voltage distortions at measurement point 740 , the values of the voltages found at the measurement point under analysis varied between $1.07 \mathrm{pu}$ (phase A), $1.01 \mathrm{pu}$ (phase B), and $1.06 \mathrm{pu}$ (phase C). In this particular case, a small difference in phases A and $\mathrm{C}$ may be observed, approximately the range considered adequate in [40], which is $0.93 \mathrm{pu}$ $(2576 \mathrm{kV})$ to $1.05 \mathrm{pu}(2908 \mathrm{kV})$.

In the voltage harmonics, the distortion was within limits established by the standard. The total harmonic distortion was $1.05 \%$ for phase A, $1.02 \%$ for phase B, and $1.19 \%$ for phase $C$, and the limit stipulated by the legislation was $5 \%$. The harmonic of greater amplitude in the three phases was the 3rd. Generally, the harmonics that presented greater values of harmonic voltage distortion were the 3rd, 5th, and 7th harmonics, where the 3rd harmonic reached a maximum value of $0.79 \%$, the 5 th harmonic reached a maximum value of $0.71 \%$, and the 7 th harmonic reached $0.52 \%$ when the maximum allowed value was $3 \%$.

Based on the evaluation performed, measurement point 740 complied with the standards and resolutions of the harmonics in [41]. Nevertheless, with the voltage limits, a small extrapolation in phases $\mathrm{A}$ and $\mathrm{C}$ was observed.

\subsection{Analysis of Harmonic Currents (IHDI and THDI)}

Figure 17 shows the values recorded for photovoltaic systems located at points 712, $718,720,729,730,731,737$, and 740 for individual current distortions in the three phases (A, B, and C) obtained over the monitoring time in the shape of the frequency spectrum.

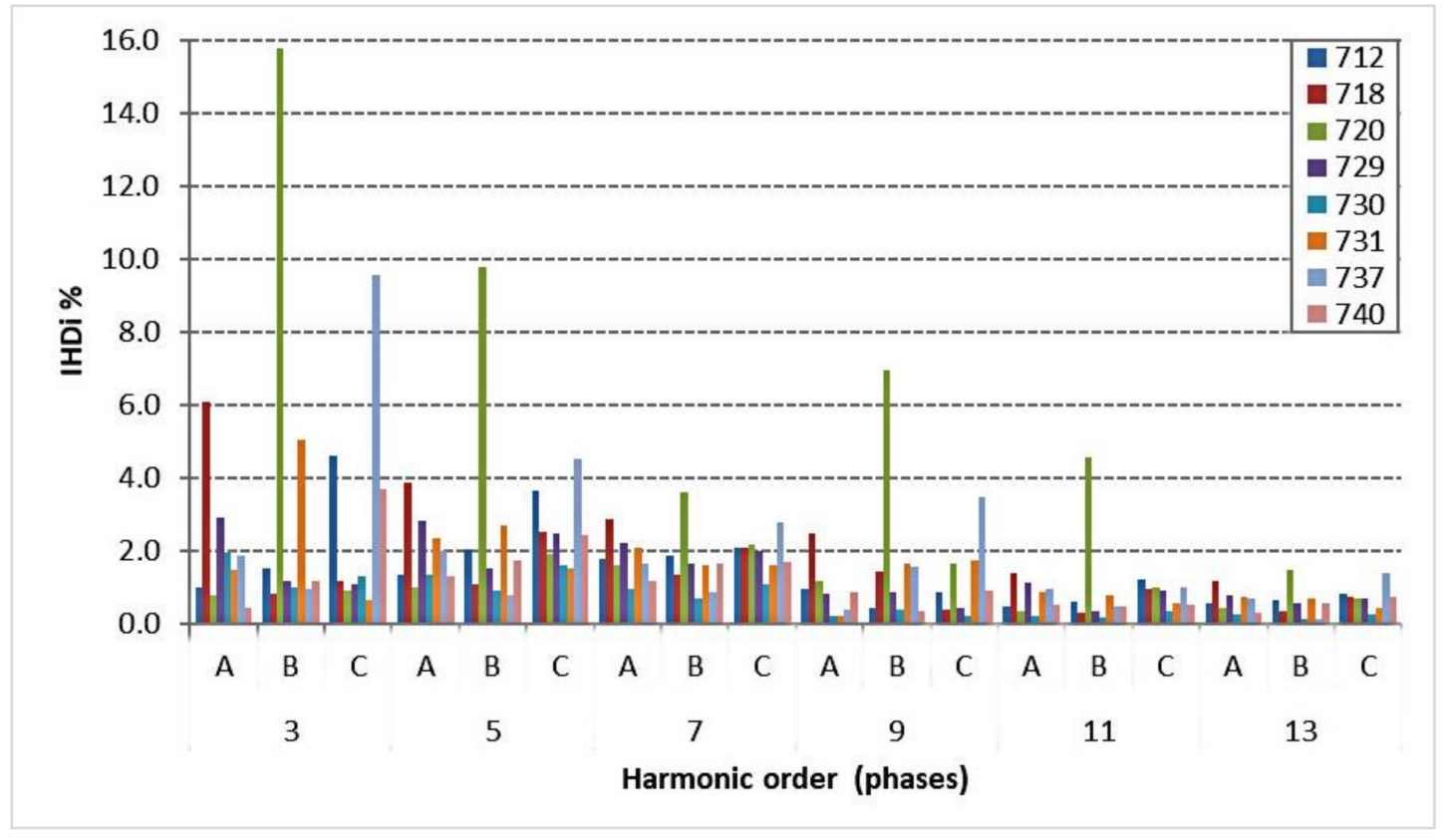

Figure 17. IHDi spectrum at IEEE 37 bus PV systems.

Equation (4) was used to determine the values of the total harmonic current distortions in the respective phases A, B, and C at nodes 712, 718, 720, 729, 730, 731, 737, and 740, which are represented in Figure 18.

$$
T H D i=\sqrt{\sum_{h=2}^{h=\text { máx }} \frac{i_{h}^{2}}{i_{1}^{2}}} \cdot 100 \%
$$




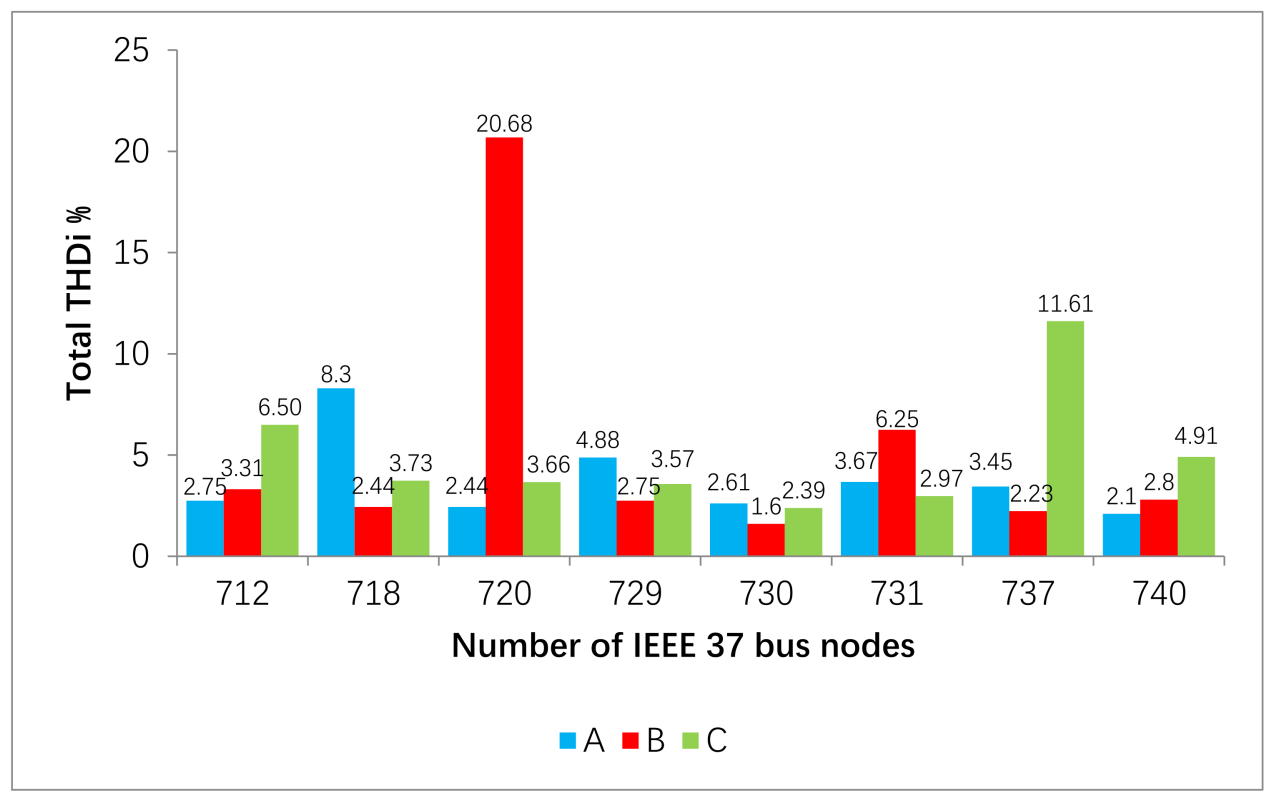

Figure 18. Total THDi spectrum per phase in IEEE 37 bus PV systems.

Table 8 shows the IEEE 519 harmonic current limits. The harmonic current limits specify the maximum amount of harmonic current that the customer can inject into the utility system.

Table 8. Current distortion limits according to the IEEE 519 standard.

\begin{tabular}{cc}
\hline \multicolumn{2}{c}{ Maximum Harmonic Current Distortion } \\
\hline Harmonic Ord & Individual Harmonic (\%) \\
\hline$<11$ & 4 \\
$11 \leq \mathrm{n}<17$ & 2 \\
$17 \leq \mathrm{n}<23$ & 1.5 \\
$23 \leq \mathrm{n}<35$ & 0.6 \\
$35 \leq \mathrm{n}$ & 0.3 \\
\hline Total harmonic distortion THDi $(\%)$ & 5.0 \\
\hline
\end{tabular}

According to Table 8 and Figures 17 and 18, nodes 712, 718,720, 731, and 737 violated the international standard IEEE 519:2014. Nodes 729, 730, and 740 remained within the standard.

The analysis of the current distortions at the PV-712 measurement point, considering that the relationship between the harmonic components of the current in relation to its fundamental element of the measured signal, allowed individual harmonics of the currents to reach a maximum of $4 \%$ for the odd harmonics of the 3rd to the 9 th orders and $2 \%$ for the odd harmonics from 11th to 15th orders. According to IEEE519-2014 [41], it was observed that the 3rd harmonic relative to phase $C$ exceeded this limit, reaching $4.62 \%$. The other harmonic components were within the recommended range.

The THDi at the 712 measurement point reached its maximum value of $6.50 \%$ in phase $\mathrm{C}$, while the recommended limit was $5 \%$. Therefore, it is necessary to monitor the operation of PV-712 to prevent this 3rd order harmonic in phase $\mathrm{C}$ from causing future problems for the system range.

Analysing the individual harmonic distortion of current and THDi in PV-718, it was verified that the 3rd order harmonic of current continued to be predominant about the others. This harmonic has a value of $6.07 \%$ at stage A, exceeding the stipulated $4 \%$ ceiling and influencing THDi's level at stage A to reach $8.3 \%$, which was above the allowed limit value of $5 \%$. The other harmonic components are within the recommended range. 
According to the results of the simulations performed in PV-720, the levels of individual harmonic current distortion presented values above the limit value of $4 \%$ in phase $\mathrm{B}$ for harmonics of the 3rd, 5 th and 9 th orders, which reached $15.77 \%$, 9.78\%, and $6.94 \%$, respectively.

The value found for the harmonic $11^{\circ}$ exceeded the limit value of $2 \%$, reaching $4.58 \%$ in phase $\mathrm{B}$, not being within the parameters established by the standards, procedures, and recommendations in force. The other phases $\mathrm{A}$ and $\mathrm{C}$ were within the recommended range.

The THDi recorded at this measurement point was $20.68 \%$ in phase $B$, and the recommended limit was $5 \%$. Therefore, this was a very high percentage that did not obey the established limitation and would be influenced negatively in the system. It was also possible to observe that the other phases $A$ and $C$ presented the levels within the established standards and recommendations in force. The high THDi value in phase B referring to node 720 was related to the lower magnitude of the fundamental current in this phase. This issue caused a higher percentage of active power loss to the other lines, as one can see in Table 6 (Line 8) and the graph in Figure 12.

Analysing the individual harmonic distortion of current in PV-731, as shown in Figure 17, and THDi, in Figure 18, it was verified that the harmonics of the 3rd, 5th, and 7th orders remained predominant in relation to the others with values, respectively equal to $5.04 \%$ and $2.70 \%$ in stage $\mathrm{B}$ and $2.11 \%$ in stage $\mathrm{A}$, but the percentage corresponding to the $3 \mathrm{rd}$ harmonic in phase $B$ was above the maximum limit of $4 \%$, which indicated a value violation for the system.

The highest percentage of THDi occurred in phase B at $6.25 \%$, staying the same out of the limit range of $5 \%$. The remaining phases $\mathrm{A}$ and $\mathrm{C}$ remained within the permitted and recommended limits.

In PV-737, individual harmonic distortion showed a higher percentage in phase $\mathrm{C}$ for most harmonic orders except for the 11th; the harmonics of the 3rd and 5th orders presented values of $9.56 \%$ and $4.53 \%$, being above the allowed and recommended limit value of $4 \%$, as shown in Figure 17.

The THDi level presented a percentage above $5 \%$ for phase $C$, whose value of $11.61 \%$ was higher than expected, as shown in Figure 19. Phases A and B were balanced and complied with the acceptable limit of $5 \%$, thus not impacting THDi.

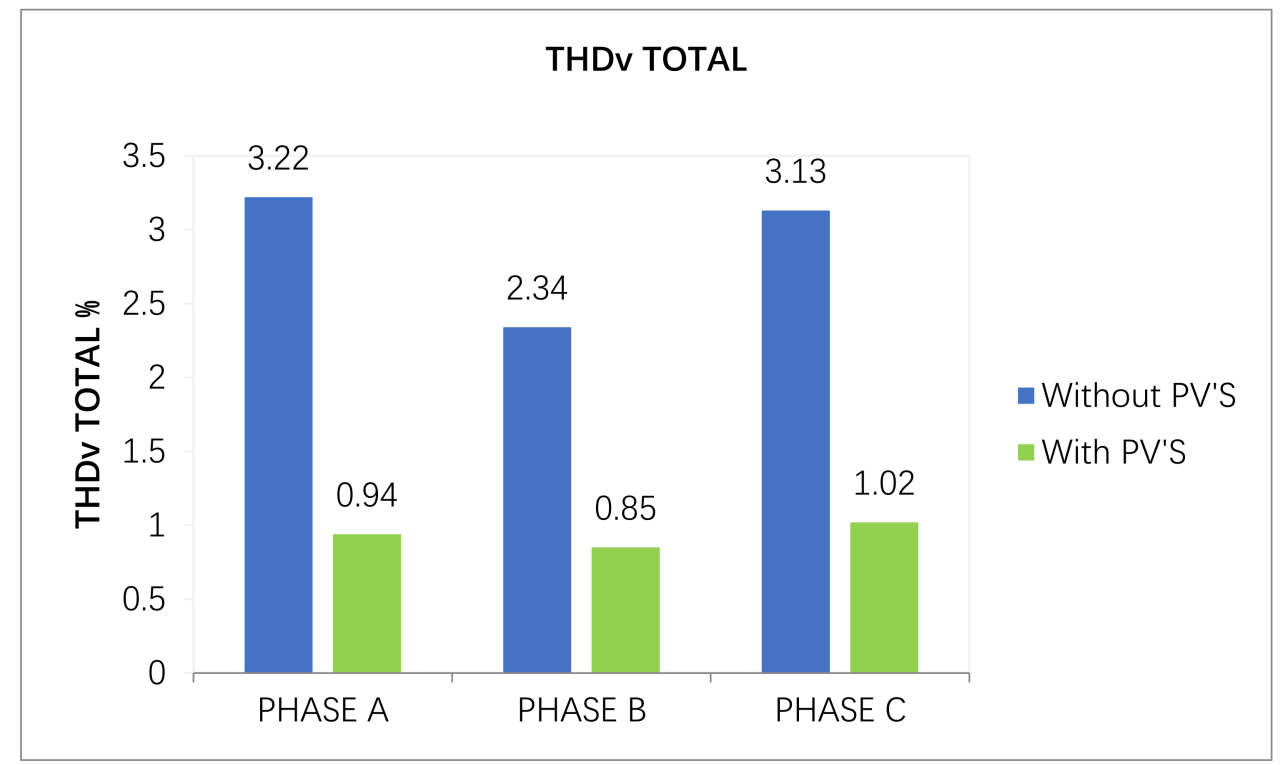

Figure 19. THDv comparative spectrum on IEEE 37 bus.

\subsection{THDv and THDi Comparative Levels with the Presence and Absence of Photovoltaic Systems}

Meter L22 recorded THDv and THDi values both in the absence and presence of photovoltaic systems on the IEEE 37 bus. The comparative levels of THDv with the absence 
and insertion of photovoltaic systems presented values within the standards of IEEE 519. The compared values shown in Figure 19 display a decrease in terms of percentage values for THDv values with the presence of photovoltaic systems. It is possible to infer that the installation of photovoltaic systems did not negatively impact the transgression of THDv values because THDv values did not violate the limits of IEEE 519 after insertion of the photovoltaic systems.

The comparative level of THDi in Figure 20 exceeded the limit of $5 \%$ established by IEEE 519 in phase B when PVs were present, and the value of THDi in phase A almost doubled its value from that established without the presence of photovoltaic systems but remained within the standards.

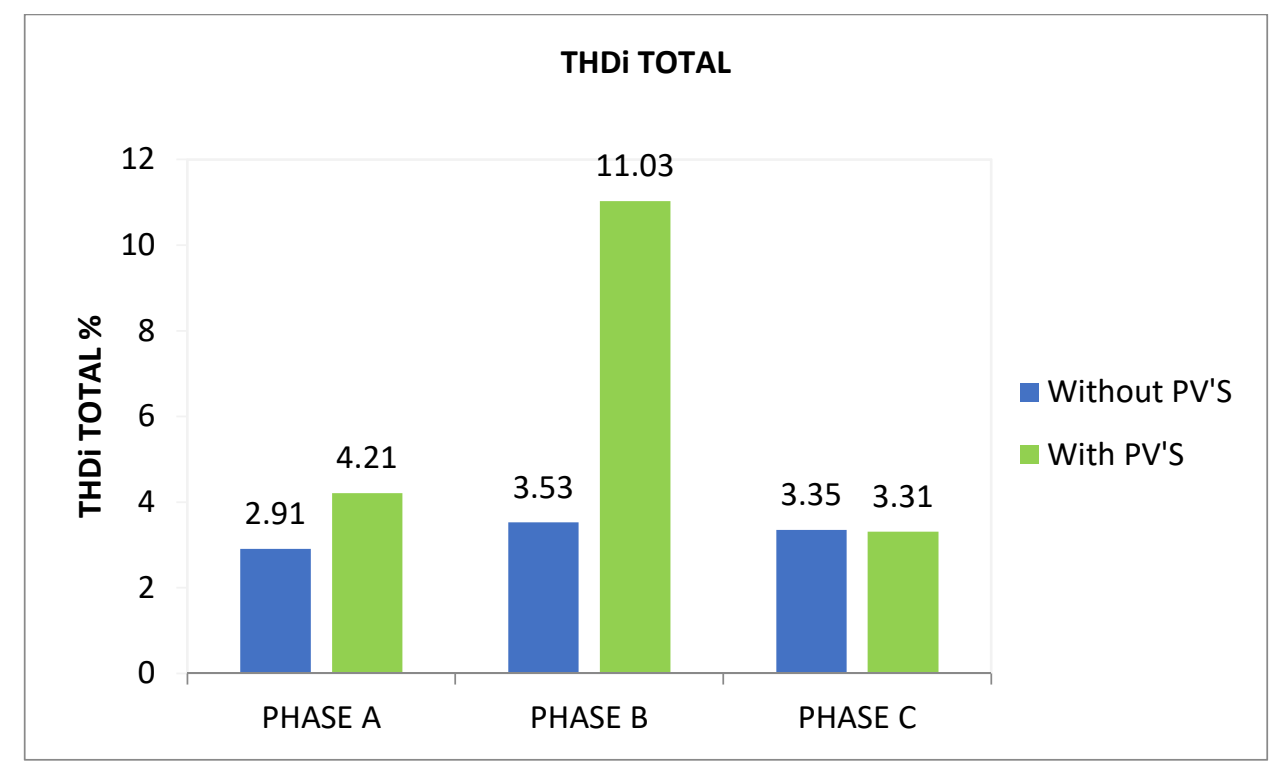

Figure 20. THDi Comparative Spectrum on IEEE 37 bus.

The use of transformers with the delta-star (Dy) connection can be used to reduce the distortions caused by the 3rd harmonic. It is an option to ensure the quality energy to end consumers.

\section{Conclusions}

This paper analysed the harmonic levels produced by the high penetration of PV systems in distribution networks using the OpenDSS, which is widely used by most concessionaires for the detection of harmonic sources.

A detailed analysis of the effects of harmonics due to the high penetration of photovoltaic generation into a distribution network provided useful information to identify the main effects resulting from the harmonic insertion process into a distribution system. The results obtained in the simulations demonstrate that under specific conditions, the voltage profile in phases $A$ and $C$ was higher in scenario 2 than in scenario 1 but remained within the acceptable range ( 0.96 to 1.05 ) in pu. The demand for reactive power was substantially increased in the main generation system due to the insertion of photovoltaic systems because photovoltaic systems are not able to provide reactive power to the system network, resulting in a decrease in the overall system power factor. Losses were better distributed with the presence of photovoltaic systems than without them.

According to the study, the presence of total and individual harmonic distortions is a major factor influencing the characteristics of a distribution system. The highest values of voltage distortion and harmonic current were observed in the 3rd, 5th, and 7th harmonics, not violating in extreme proportions the standard voltage limits at the connection points. However, it has been shown that in regard to current distortions, individual or total results reported in this article lead to noncompliance with the established standards and provide 
strong evidence indicating that they are more harmful and may cause future problems for distribution due to the high penetration of photovoltaic generation. To mitigate the effects of IHD and THD voltage and current, filters must be used in the inverters related to nodes $712,718,720,731$, and 737 . The results reported in this article also provide strong evidence indicating that the advantage stemming from the high insertion of photovoltaic generation in distribution systems is performed in a more uniform and balanced manner on both sides of the system concerning energy demand. In addition, it has been shown that the insertion of high photovoltaic generation in distribution systems increases the amount of current passing through the stretches, thus requiring less substation transformer effort to load the distribution network, creating a high energy production level that results in a high surplus injected into the network and, as a consequence, increased losses. Therefore, this further confirms our initial hypothesis, where the effects of harmonics due to the high penetration of photovoltaic generation in the distribution system act as agents impacting systemic functionality based on the differences described in scenario 1 when compared to scenario 2 . The high penetration of photovoltaic systems consequently shows a decrease in the voltage THDv and an increase in the current THDi.

Author Contributions: Conceptualization, J.L.M.P.; methodology, J.L.M.P. and A.F.R.L.; software, J.L.M.P.; formal analysis, J.L.M.P., A.F.R.L., G.O.d.A., and M.E.d.L.T.; data curation, J.L.M.P.; writingreview and editing J.L.M.P., A.F.R.L., G.O.d.A., and M.E.d.L.T.; supervision, A.F.R.L., and M.E.d.L.T. All authors have read and agreed to the published version of the manuscript.

Funding: This research received no external funding.

Data Availability Statement: Not applicable.

Acknowledgments: The authors would like to thank Davis Montenegro, Celso Rocha, and Paulo Radatz for useful discussion on the OpenDSS.

Conflicts of Interest: The authors declare no conflict of interest.

\section{References}

1. National Association of Clean Air Agencies (NACAA). Implementing EPA's Clean Power Plan: A Menu of Options. Chapter 10. Reduce Losses in the Transmission and Distribution System; NACAA: Washington, DC, USA, 2015.

2. Schinke, A.; Erlich, I. Enhanced voltage and frequency stability for power systems with high penetration of distributed photovoltaic generation. IFAC-Papercept 2018, 51, 31-36. [CrossRef]

3. Ebad, M.; Grady, W.M. An approach for assessing high-penetration PV impact on distribution feeders. Electr. Power Syst. Res. 2016, 133, 347-354. [CrossRef]

4. Anzalchi, A.; Sundararajan, A.; Moghadasi, A.; Sarwat, A. Power quality and voltage profile analyses of high penetration grid-tied photovoltaics: A case study. In 2017 IEEE Industry Applications Society Annual Meeting; IEEE: Cincinnati, OH, USA, 2017; pp. 1-8.

5. Anurangi, R.O.; Rodrigo, A.S.; Jayatunga, U. Effects of high levels of harmonic penetration in distribution networks with photovoltaic inverters. In Proceedings of the 2017 IEEE International Conference on Industrial and Information Systems (ICIIS), Peradeniya, Sri Lanka, 15-16 December 2017; pp. 1-6.

6. Barutcu, I.C.; Karatepe, E.; Boztepe, M. Impact of harmonic limits on PV penetration levels in unbalanced distribution networks considering load and irradiance uncertainty. Int. J. Electr. Power Energy Syst. 2020, 118, 105780. [CrossRef]

7. Sinvula, R.; Abo-Al-Ez, K.M.; Kahn, M.T. Total harmonics distortion (THD) with PV System integration in smart grids: Case study. In Proceedings of the 2019 International Conference on the Domestic Use of Energy (DUE), Wellington, South Africa, 25-27 March 2019; pp. 102-108.

8. Fang, W.; Huang, Q.; Huang, S.; Yang, J.; Meng, E.; Li, Y. Optimal sizing of utility-scale photovoltaic power generation complementarily operating with hydropower: A case study of the world's largest hydro-photovoltaic plant. Energy Convers. Manag. 2017, 136, 161-172. [CrossRef]

9. Colmenar-Santos, A.; Linares-Mena, A.-R.; Molina-Ibáñez, E.L.; Rosales-Asensio, E.; Borge-Diez, D. Technical challenges for the optimum penetration of grid-connected photovoltaic systems: Spain as a case study. Renew. Energy 2020, 145, 2296-2305. [CrossRef]

10. Kerdoum, P.; Premrudeepreechacharn, S. Analysis of PV penetration level on low voltage system in Chiang Mai Thailand. Energy Rep. 2020, 6, 754-760. [CrossRef]

11. Kyritsis, A.; Voglitsis, D.; Papanikolaou, N.; Tselepis, S.; Christodoulou, C.; Gonos, I.; Kalogirou, S.A. Evolution of PV systems in Greece and review of applicable solutions for higher penetration levels. Renew. Energy 2017, 109, 487-499. [CrossRef] 
12. Pereira, H.A.; Freijedo, F.D.; Silva, M.M.; Mendes, V.F.; Teodorescu, R. Harmonic current prediction by impedance modeling of grid-tied inverters: A 1.4MW PV plant case study. Int. J. Electr. Power Energy Syst. 2017, 93, 30-38. [CrossRef]

13. Seme, S.; Lukač, N.; Štumberger, B.; Hadžiselimović, M. Power quality experimental analysis of grid-connected photovoltaic systems in urban distribution networks. Energy 2017, 139, 1261-1266. [CrossRef]

14. McBee, K.D. Transformer aging due to high penetrations of PV, EV charging, and energy storage applications. In Proceedings of the 2017 Ninth Annual IEEE Green Technologies Conference (GreenTech), Denver, CO, USA, 29-31 March 2017; pp. 163-170.

15. Sakar, S.; Balci, M.E.; Abdel Aleem, S.H.E.; Zobaa, A.F. Increasing PV hosting capacity in distorted distribution systems using passive harmonic filtering. Electr. Power Syst. Res. 2017, 148, 74-86. [CrossRef]

16. Srinath, S.; Poongothai, M.S.; Aruna, T. PV integrated shunt active filter for harmonic compensation. Energy Procedia 2017, 117, 1134-1144. [CrossRef]

17. Patsalides, M.; Efthymiou, V.; Stavrou, A.; Georghiou, G.E. A generic transient PV system model for power quality studies. Renew. Energy 2016, 89, 526-542. [CrossRef]

18. Alhafadhi, L.; Teh, J. Advances in reduction of total harmonic distortion in solar photovoltaic systems: A literature review. Int. J. Energy Res. 2020, 44, 2455-2470. [CrossRef]

19. Kopicka, M.; Ptacek, M.; Toman, P. Analysis of the power quality and the impact of photovoltaic power plant operation on low-voltage distribution network. In Proceedings of the 2014 Electric Power Quality and Supply Reliability Conference (PQ), Rakvere, Estonia, 11-13 June 2014; pp. 99-102.

20. Osma-Pinto, G.; García-Rodríguez, M.; Moreno-Vargas, J.; Duarte-Gualdrón, C. Impact evaluation of grid-connected PV systems on PQ parameters by comparative analysis based on inferential statistics. Energies 2020, 13, 1668. [CrossRef]

21. Abas, N.; Dilshad, S.; Khalid, A.; Saleem, M.S.; Khan, N. Power quality improvement using dynamic voltage restorer. IEEE Access 2020, 8, 164325-164339. [CrossRef]

22. Zare, F.; Soltani, H.; Kumar, D.; Davari, P.; Delpino, H.A.M.; Blaabjerg, F. Harmonic emissions of three-phase diode rectifiers in distribution networks. IEEE Access 2017, 5, 2819-2833. [CrossRef]

23. Sinvula, R.; Abo-Al-Ez, K.M.; Kahn, M.T. Harmonic source detection methods: A systematic literature review. IEEE Access 2019, 7, 74283-74299. [CrossRef]

24. Macêdo, W.N.; Zilles, R. Influence of the power contribution of a grid-connected photovoltaic system and its operational particularities. Energy Sustain. Dev. 2009, 13, 202-211. [CrossRef]

25. Chidurala, A. High Penetration of PV Systems in Low Voltage Distribution Networks: Investigation of Power Quality Challenges and Mitigation. Ph.D. Thesis, School of Information Technology and Electrical Engineering, The University of Queensland, Brisbane, Australia, 2016.

26. Zhang, J.; Isobe, T.; Tadano, H. Model-based control for grid-tied inverters operated in discontinuous current mode with low harmonic current distortion. IEEE Trans. Power Electron. 2020, 35, 11167-11180. [CrossRef]

27. Chidurala, A.; Kumar Saha, T.; Mithulananthan, N. Harmonic impact of high penetration photovoltaic system on unbalanced distribution networks-learning from an urban photovoltaic network. IET Renew. Power Gener. 2016, 10, 485-494. [CrossRef]

28. Schlabbach, J.; Grob, A.; Chicco, G. Influence of harmonic system voltages on the harmonic current emission of photovoltaic inverters. In Proceedings of the 2007 International Conference on Power Engineering, Energy and Electrical Drives, Setubal, Portugal, 12-14 April 2007; pp. 545-550. [CrossRef]

29. Kouveliotis-Lysikatos, I.; Kotsampopoulos, P.; Hatziargyriou, N. Harmonic Study in LV Networks with high penetration of PV systems. In Proceedings of the 2015 IEEE Eindhoven PowerTech, Cluj-Napoca, Romania, 29 June-2 July 2015; pp. 1-6.

30. Pereira, C.A.N.; Lopes, J.A.P.; Matos, M.A.C.C. Assessment of the distributed generation hosting capacity incorporating harmonic distortion limits. In Proceedings of the 2018 International Conference on Smart Energy Systems and Technologies (SEST), Seville, Spain, 10-12 September 2018; pp. 1-6.

31. Awadallah, M.A.; Venkatesh, B.; Singh, B.N. Impact of solar panels on power quality of distribution networks and transformers. Can. J. Electr. Comput. Eng. 2015, 38, 45-51. [CrossRef]

32. Kharrazi, A.; Sreeram, V.; Mishra, Y. Assessment techniques of the impact of grid-tied rooftop photovoltaic generation on the power quality of low voltage distribution network-A review. Renew. Sustain. Energy Rev. 2020, 120, 109643. [CrossRef]

33. Patsalides, M.; Evagorou, D.; Makrides, G.; Achillides, Z.; Georghiou, G.E.; Stavrou, A.; Werner, J.H. The effect of solar irradiance on the power quality behaviour of grid connected photovoltaic systems. Int. Conf. Renew. Energy Power Qual. 2007, 1, 323-330. [CrossRef]

34. Chicco, G.; Schlabbach, J.; Spertino, F. Experimental assessment of the waveform distortion in grid-connected photovoltaic installations. Sol. Energy 2009, 83, 1026-1039. [CrossRef]

35. Rajapakse, A.D.; Muthumuni, D. Simulation tools for photovoltaic system grid integration studies. In Proceedings of the 2009 IEEE Electrical Power \& Energy Conference (EPEC), Montreal, QC, Canada, 22-23 October 2009; pp. 1-5.

36. Sa'ed, J.A.; Quraan, M.; Samara, Q.; Favuzza, S.; Zizzo, G. Impact of integrating photovoltaic based DG on distribution network harmonics. In Proceedings of the 2017 IEEE International Conference on Environment and Electrical Engineering and 2017 IEEE Industrial and Commercial Power Systems Europe (EEEIC/I\&CPS Europe), Milan, Italy, 6-9 June 2017; pp. 1-5.

37. Dugan, R.C.; Montenegro, D. Reference Guide: The Open Distribution System Simulator (OpenDSS); Electric Power Research Institute (EPRI), Inc: Washington, DC, USA, 2019. 
38. IEEE Power \& Energy Society (IEEE PES AMPS DSAS Test Feeder Working Group). Available online: https://site.ieee.org/pestestfeeders / (accessed on 15 March 2020).

39. Dugan, R.C. Reference Guide: OpenDSS PVSystem Element Model; Electric Power Research Institute (EPRI), Inc.: Washington, DC, USA, 2019.

40. National Electrical Manufacturers Association. American National Standards Institute (ANSI) C84.1-2006, Voltage Ratings for Electric Power Systems and Equipment, Power Quality; NEMA: Rosslyn, VA, USA, 2006.

41. Institute of Electrical and Electronics Engineers (IEEE). IEEE Recommended Practice and Requirements for Harmonic Control in Electric Power Systems-Redline in IEEE Std 519-2014 (Revision of IEEE Std 519-1992)-Redline; IEEE: New York, NY, USA, 2014. 